\title{
Teil V: Decorative Strategien im Wandel der Zeit
}

Decor-Formen und Decor-Inhalte, die zwischen Republik und Kaiserzeit zum Einsatz kamen, waren Gestaltungsprinzipien verpflichtet, die darauf abzielten, dass eine Ausstattung für ein Ambiente passend war. Architektur und Ausstattungselemente wurden ästhetisch-visuell, bisweilen auch semantisch aufeinander bezogen und nahmen zugleich auf (sozial durchwirkte) Nutzungsformen Rücksicht. Die Adäquatheit der Ausstattung richtete sich auf atmosphärisch relevante Aspekte, die im Folgenden noch einmal historisch vergleichend zur Sprache kommen sollen ${ }^{1}$ : Offenheit und Geschlossenheit; Symmetrie, Rhythmus und Axialität; Zentralität und Liminalität; Raumvolumina; Licht und Farbe; Klang und Geräusch; ,Ornament‘ und ,Bild‘; Metalepsen; Decor-Ensembles; Alt und Neu; Grand und Humble. Was jedoch als passend und angemessen galt, unterlag zwischen dem 2.Jh.v.Chr. und dem 1.Jh.n.Chr. einem erheblichen Wandel. Dementsprechend nahm die Behandlung der genannten Raum- und Decor-Qualitäten immer wieder neue Formen an. Gerade eine historisch vergleichende Betrachtung ermöglicht es folglich, wahrnehmungspsychologisch fundierte Gestaltprinzipien in ihrer historisch wandelbaren Ausprägung nachzuverfolgen.

\section{Offenheit und Geschlossenheit}

$\mathrm{Zu}$ den atmosphärisch besonders wirksamen Qualitäten zählen Offenheit und Geschlossenheit, Weite und Enge. Sie lassen sich als Gestaltungskategorien des architektonischen Raumes auffassen, aber auch als mentale Kategorien des durch den Wand-Decor vorgestellten Raumes.

\subsection{Die Abschließung des Hauses nach außen}

Offenheit und Geschlossenheit definierten zunächst einmal das Verhältnis des Hauses zur Straße. Die Fassadenwirkung von Häusern unterschied sich maßgeblich darin, ob die Front für die Anlage von Tabernae genutzt wurde oder nicht. Tabernae öffneten sich, ihrer ökonomischen Funktion entsprechend, auf ganzer Front zur Straße und verliehen einer Insula den Charakter einer offenen ,Mall'. Das eigentliche Haus trat bei dieser wirtschaftlichen Nutzung nur in Gestalt des Hauseingangs in Erscheinung. Verzichtete man auf die Anlage von Tabernae - etwa, weil sich das Haus in einer kleinen Nebenstraße befand - so prägten geschlossene Hausaußenwände das Bild.

Die Fassadengestaltung des 2. und 1.Jhs.v. Chr. unterstrich den Eindruck von Geschlossenheit. Das Tuffquadermauerwerk verlieh den Häusern eine massive, geradezu wehrhafte Front gegenüber der Straße. Für den zweiten und dritten Stil fehlen erhaltene Putzfassaden. Ein Ausblick auf den vierten Stil macht jedoch deutlich, dass man an der Idee der geschlossenen Fassade festhielt. Die Imitation von Quaderfassaden des ersten Stils, Zebrastreifen und Schachbrettmuster, nicht zuletzt die einfacheren zweifarbigen Lösungen fassten die Fassade als geschlossene Wand oder doch opake Fläche auf².

Damit kontrastierten die hohen und weiten, durch Pilaster betonten Hauseingänge, die den Übergang zwischen Draußen und Drinnen markierten. Die Doppelflügeltüren mit ihrem KassettenDecor und ihren Ziernägeln dürften den Eindruck von Geschlossenheit verstärkt haben ${ }^{3}$. Insbeson-

1 Diese Auswertung rekurriert auf vorausgegangene Überlegungen, auf Rückverweise wird jedoch verzichtet, da sich sonst eine unüberschaubare Zahl weiterer Fußnoten ergäbe. Anmerkungen werden nur dann eingefügt, wenn zusätzliche Überlegungen eingeführt werden.

2 Ausführlich zur Gestalt der Straßenräume demnächst Lauritsen.

3 Mattern 1999, 15f. zur Decor-Typologie antiker Türen; vgl. Oremus 2012, 16; zum Beispiel der Casa dei Ceii (I 6,15), Oremus 2012, 59f. $62 \mathrm{f}$. 
dere die Außentüren eines Hauses waren mit aufwendigen Verschlussmechanismen ausgestattet ${ }^{4}$. Oberhalb der Türflügel waren die Türen jedoch offen, wie Gipsabgüsse von Hausaußentüren und Wandmalereien belegen. In der Durchgangssituation selbst waren Geschlossenheit und Offenheit damit optisch aufeinander bezogen.

Dies gilt noch einmal mehr, wenn man die differenzierten Zugangslösungen der Häuser mit ihren gestaffelten, bisweilen über Eck angeordneten Türen in Rechnung stellt ${ }^{5}$. Prothyron und Fauces kann man in diesem Sinne als Räume des Übergangs verstehen, die eine Regulierung des Zugangs, eine Beschränkung des Blicks, aber auch einen Schutz vor Lärm und Gerüchen der Straße leisteten. Eine doppelte Sicherung erklärt sich jedoch nur dann, wenn man voraussetzt, dass die Türen einen direkten Zutritt und Einblick in das Haus verhinderten. So wäre bei Häusern mit einem Eingang über Eck die Haupttür in der Hausachse auch bei Tag verschlossen geblieben, während bei Häusern mit in einer Achse gestaffelten Türen die Außentür geöffnet, die Innentür verriegelt zu denken wäre. Bei einfacheren Häusern entfiel das Prothyron zumeist ganz, bei den kleinsten Häusern ist auch für die Fauces kein Platz. Dies wiederum bedeutet, dass vor allem die vermögenden Hausbesitzer den Zugang zu ihrem Haus wie auch die Blicke in das Haus in besonderem Maße kontrollierten und regulierten ${ }^{6}$. Selbst wenn die inneren Türen offen gestanden haben, dürfte der Eingang durch Pförtner (ianitor) oder Hunde kontrolliert worden sein ${ }^{7}$.

Vor diesem Hintergrund lassen sich auch Schriftquellen daraufhin befragen, ob die Eingangstüren geöffnet oder geschlossen waren. In Bezug auf die Salutatio erwähnen Quellen, dass die Klienten beim Besuch eines Hauses an der Tür anklopften ${ }^{8}$. Bei Plutarch ist der Hausbesitzer Euklio beunruhigt, als er vom Einkauf zurückkehrt und sein Haus offenstehend vorfindet - er fürchtet Einbrecher ${ }^{9}$. In Catulls Hochzeitsgedicht sollen der Jungfrau, die sich nachts dem Haus des Bräutigams naht, die geschlossenen Türen geöffnet werden ${ }^{10}$. Literarische Quellen bestätigen somit, dass die Haustüren geschlossen imaginiert wurden ${ }^{11}$.

Darüber hinaus lassen sich auch Wandmalereien und Pavimente auf ihre mentale Konzeption des Hauses hin befragen. Gemalte Prunkarchitekturen des zweiten Stils stellen üblicherweise geschlossene Gebäude dar, ein Durchblick ergibt sich allein über die Tür hinweg. Auch Pavimente bringen die Abschließung des Hauses zum Ausdruck. Das Fauces-Mosaik der Casa di Paquius Proculus/Cuspius Pansa (I 7,1) zeigt eine zweiflügelige Eingangstür von außen (Abb. 382). Ein Türflügel ist geöffnet, allerdings verhindert ein aggressiver Hund den Zutritt. Er hat sich vor den offenen Eingang gelagert, seine Kette ist am geschlossenen Türflügel festgemacht. Die ,cave canem Mosaiken rekurrieren damit ebenfalls auf die Idee einer besonderen Sicherung des Hauseingangs ${ }^{12}$.

Die architektonischen Lösungen, Schriftquellen und bildliche Darstellungen legen damit nahe, dass die Eingangstüren geschlossen waren und der Zutritt zum Haus kontrolliert wurde ${ }^{13}$. Mit dieser Schließung kontrastiert die Ausrichtung des Hauses auf eine Sichtachse, die auf den Eingang

4 Proudfoot 2013, 106 f.

5 Zur Diskussion von Vitr. 6,7,5, der im Zuge einer Diskussion der Begriffe Vestibulum, Prothyron und Diathyron eine solche Disposition vermeintlich für das griechische Haus beschreibt, s. Proudfoot 2013, 94; ebda. eine Typologie möglicher Zugangssituationen: direkter Zugang ohne Fauces; Zugang über Vestibül (zwei Türen); Zugang über Vestibül (zwei Türen) mit seitlichem Raum; Zugang in Fauces (eine Tür), s. Proudfoot 2013, 95 Abb. 3.

6 Proudfoot 2013, 102f. mit Verweis auf die Casa del Fauno, die Casa del Cinghiale (VIII 2,26) und die Casa del Gallo (VIII 5, 2).

7 Ov. fast. 1,137f.; s. Proudfoot 2013, 92. 104.

8 Hor. sat. 1,1,9; Sen. epist. 68,10; vgl. Platts 2020, 81.

9 Plaut. Aul. 388f.

10 Catull. 61,76f.; weitere Quellen bei Platts 2020, 81f. diskutiert.

11 Tac. ann. 2,82 berichtet uns, dass anlässlich des Todes des Germanicus die Häuser geschlossen worden seien. Ob sich dies wörtlich auf das Schließen von (sonst offenstehenden) Türen bezieht oder metaphorisch auf den Verzicht, Besuch zu empfangen, bleibt spekulativ. Die Quelle kann daher kaum als Beleg für sonst offenstehende Türen gewertet werden; vgl. Proudfoot 2013, 103; Platts 2020, $86 \mathrm{f}$.

12 Etwa Hales 2004, 110.

$13 \mathrm{Zu}$ verschiedenen Aspekten auch Proudfoot 2013, 103f.; Platts 2020, $83 \mathrm{f}$. 
bezogen ist. Dieser prominente Blick durch das Haus wäre, wenn die vorausgegangenen Überlegungen etwas Richtiges treffen, keineswegs immer möglich gewesen. Allerdings gewann die Sichtachse erst durch die Regulierung des Blicks ihre eigentliche ästhetische Wirkung und soziale Bedeutung: Für denjenigen, dem sich die Türen auftaten, dürfte die Inszenierung des Hauses besonders effektvoll erlebbar geworden sein.

\subsection{Die visuelle Organisation des Hausinneren}

Offenheit und Geschlossenheit sind nicht nur Kategorien, die das Haus in seinem Verhältnis zum urbanen Raum definierten, sondern auch zentrale Gestaltungskategorien im Hausinneren. Sie kamen bei der architektonischen Gestaltung der Höfe und Aufenthaltsräume zum Tragen, aber auch die gestalteten Wandflächen reflektierten eine Vorstellung von Offenheit und Geschlossenheit. Damit stellt sich die Frage, wie Architekturraum und imaginierter Raum aufeinander zurückwirkten.

In den Häusern des späten 2. und beginnenden 1.Jhs. besaßen die verschiedenen Hofbereiche und Aufenthaltsräume sehr unterschiedliche Raumqualitäten. Das Atrium verfügte über ein enormes umbautes Volumen, sein Licht erhielt es über eine kleine, rechteckig begrenzte Dachöffnung. Die Peristyle hingegen waren von Portiken umgeben, die sich über eine ,semipermeable‘ Säulenstellung auf einen lichten und weiten Hof öffneten. Einem eng begrenzten, gepflasterten Impluvium entsprach im Peristyl der große, offene Gartenhof. Mit den Höfen unterschieden sich die Qualitäten der an sie anschließenden Räume.

Auf das Atrium öffneten sich mit Tablinum und Alae große, hohe Räume, die visuell und funktional auf den Atriumsraum bezogen waren. Davon unterschieden sich die durch hohe, zweiflüglige Türen verschlossenen Cubicula. Diese waren, wenn überhaupt, nur durch kleine Fenster beleuchtet. War die Kline dem Eingang gegenüber platziert, so fiel das spärliche Eingangslicht auf sie. War die Kline um 90 Grad aus der Eingangsachse versetzt, blieb sie weitgehend im Dunkeln. Die Intimität des Alkovens konnte durch abgehängte Decken gesteigert werden. Mit den dunklen Cubicula kontrastierten die stattlichen Triclinia, die sich meist über große Fenster auf den Peristylhof öffneten. Bei den an den Peristylen gelegenen Exedrae mit ihren weiten Raum- und Fensteröffnungen handelt es sich um die hellsten Räume des Hauses. In der Zeit des ersten Stils verband sich somit Dunkelheit mit Intimität, Helligkeit mit Offenheit. Indem allerdings die Cubicula im vorderen Hausteil, die offenen, ,freizügigen` Exedren am rückwärtigen Peristyl lagen, waren ,Privatheit‘ und ,Öffentlichkeit‘ ineinander verschränkt. Eine ähnliche Verschränkung ergibt sich für die Cenacula. Sie öffnen sich auf ganzer Front auf einen Hof und dürften dadurch luftig und licht ausgefallen sein, waren jedoch durch ihre Lage im Obergeschoss, abgeschieden'.

Der Wand-Decor ersten Stils verzichtet auf eine Differenzierung von Innen und Außen, er repräsentiert eine geschlossene Wand. Reale Wände werden mit dem Bild einer geschlossenen Wand versehen und dadurch in ihrer Solidität verstärkt. Eine Ausnahme machen die Pilaster an den Peristylrückwänden, die ,vor‘ eine geschlossene Wand gesetzt sind. Dadurch wird eine weitere, semipermeable Stützenstellung suggeriert. Bisweilen wird ein solcher Eindruck auch durch eine Schein-Loggia im Obergeschoss erzeugt. Allerdings schließt sich die Wand hinter den Pilasterordnungen am Peristyl ebenso wie hinter den Scheinarchitekturen der Obergeschosszonen. Jeder einzelne Raum und das Haus als Ganzes sind auf allen Seiten von soliden, abgeschlossenen Mauern eingefasst.

Im Verlauf des 1.Jhs.v. Chr. änderten sich sowohl Architekturkonzepte als auch Ausstattungsformen; die verschiedenen Veränderungen fielen zeitlich allerdings nicht exakt zusammen. Die Hofbereiche folgten in Bezug auf Offenheit und Geschlossenheit gängigen Konzepten, während die Aufenthaltsräume einem größeren Wandel unterworfen waren. Die Cubicula an den Atrien zeichneten sich auch weiterhin durch ihre Höhe und relative Dunkelheit aus. Häufiger als zuvor wurde der Alkoven jedoch mit einer abgehängten Decke versehen und als intimer Raum inszeniert. An den Peristylen, die zum eigentlichen Ort des Wohnens avancierten, experimentierte man mit neuen 
Raumformen. Sie reagierten auf das Bedürfnis, Wohnräume auf den Garten zu öffnen. Nicht nur Triclinia und Oeci, sondern auch kleine und niedrige Cubicula wurden mit weiten, verschließbaren Raumöffnungen versehen. Exedren wurden kaum noch neu angelegt. Die Nutzung des Peristyls für Wohnzwecke ging mit dem Bedürfnis einer stärkeren Zugangsregulierung dieser Räume einher.

Mit der neuen Vorliebe für Ausblicke in den Garten änderte sich die malerische Konzeption der Wandfläche. Die Rückwände des Atriums zeigten weiterhin geschlossene Architekturen, selbst auf vor die Wand gesetzte Säulen verzichtete man meist. Auch in den dunklen Cubicula am Atrium, von denen aus man auf einen architektonisch gestalteten Innenraum blickte, verstärkte die Wandmalerei die Raumwahrnehmung: Es handelt sich um Räume im ,Zentrum‘ des Hauses, die von Architektur umgeben, mithin geschlossen sind. Für die Peristylrückwände schätzte man es offensichtlich, die traditionelle Pilasterordnung beizubehalten, die den semipermeablen Raum der Portiken optisch verdoppelte. Anders nahm sich - wieder in der Tendenz - die Ausmalung der Räume aus, die sich auf den Garten öffneten ${ }^{14}$. Das Spiel mit Offenheit und Geschlossenheit, Licht und Dunkelheit, das durch Raumöffnungen und Verschlussmechanismen erzeugt wurde, hat man in einigen Räumen in ein Spiel mit Geschlossenheit und Offenheit des Wandbildes überführt. In den ,Gartenräumen' öffnete sich der Ausblick nicht mehr nur in die reale Landschaft, sondern auf den Wänden auch in fiktive ,Architekturlandschaften'. Dies schloss ein Spiel mit Realität und Illusion ein, verschiedene Realitätsgrade und Medien traten in Beziehung zueinander. Allerdings bleiben die Gelageteilnehmer in den Triclinia und Cubicula von geschlossenen Rückwänden umgeben: Scherwände schlossen auf den Wandbildern die Mittelzone. Virtuelle Ausblicke blieben (schon) im zweiten Stil auf die Oberzone beschränkt.

Mit dem Übergang zur Kaiserzeit wurden Offenheit und Geschlossenheit in neuartiger Weise aufeinander bezogen. Die Architektur inszenierte den Ausblick auf die Gartenareale noch einmal gezielter. Dies gilt bereits für das Atrium, das über Blickachsen auf den Garten bezogen werden konnte. Besonders explizit geschieht dies in Häusern wie der Casa di P. F. L. (IX 6,3), in denen das Tablinum zugunsten einer Schauwand wegfiel, deren symmetrisch arrangierte Durchgangstüren den Blick in den Garten rahmten. Es gilt aber ebenso für Aufenthaltsräume - die in ihrer Größe erheblich gesteigerten Prunkräume wie die intimen Diaetae. Dafür kamen verschiedene Strategien zum Tragen. Zum einen wurden Gelageräume asymmetrisch platziert, sodass sich von der zentralen Kline ein möglichst optimaler Blick auf die gestaltete Peristylrückwand ergeben konnte. So blickte man in der Casa annessa alla Casa dell'Efebo $(\mathrm{I} 7,19)$ von der rückwärtigen Liege des leicht dezentralen Aufenthaltsraumes symmetrisch auf die Gartenmalerei an der Rückwand des Rumpfperistyls (Abb. 345). Zum anderen wurde der Ausblick in den Garten nach Möglichkeit gerahmt. In der Casa di Marcus Lucretius Fronto bilden die Tablinumsöffnungen eine doppelte Rahmung für den Blick vom Atrium ins Peristyl. Vom Triclinium (f) der Casa di Giasone blickte man zwischen zwei Peristylsäulen hindurch auf den Garten mit einem Wasserspiel (Abb. 261), während der Ausblick von Cubiculum (20) der Casa del Citarista (I 4,5.6.25.28) in Peristyl (17) durch mehrere, gestaffelte Rahmungen gestaltet wurde (Abb. 318). Der Blick durchquert verschiedene Schranken, sein Ziel - der Garten - ist ein Ort außerhalb, an dem sich der Betrachter nicht befindet, ein ,Heterotopos'.

Allerdings wurde nicht nur der Ausblick auf den Garten, sondern auch der Blick auf die Räume am Garten gestaltet. Durch die Schaffung von symmetrischen Raumgruppen wurde der Gartenprospekt regelrecht bildhaft inszeniert. In der Casa di Sallustio wurden die Diaetae etwa als Pendants, die den Garten flankieren, konzipiert (Abb. 320). Dieses Bild erschloss sich jedoch nur einem Nutzer ,außerhalb' der Räume, nicht den Conviviums-Teilnehmern, die sich bereits in den Räumen eingefunden hatten. Blickoptionen sind so in noch einmal neuartiger Weise ineinander verschränkt worden.

14 In der Forschung beschränken sich die Überlegungen meist darauf, dass Räume mit Aussicht ein ,offenes` System erhielten, s. etwa Heinrich 2002, 55-67; Ehrhardt 2012, 14. 
$\mathrm{Zu}$ einer Neubestimmung von Innen und Außen trug in der frühen Kaiserzeit nicht zuletzt die Gestaltung der Peristylgärten bei. Durch die Anlage von Nymphäen und Brunnen sowie durch die Aufstellung von Skulpturen wurden sie zu regelrechten Schaugärten. In den Interkolumnien aufgehängte Oscilla, hier aufgestellte Skulpturen, auch Vorhänge, ephemere Schranken (Zäune) sowie niedrige Gartenmauern ${ }^{15}$ rahmten den Blick und schränkten das Betreten des Gartens ein. Gartentriclinia bezeugen indes, dass der Garten zumindest in einigen Fällen auch als Aufenthaltsraum in Anspruch genommen wurde.

Mit der konsequenten Ausrichtung der Wohnräume zum Garten hin ging eine ,Schließung، des gemalten Wandaufbaus einher. Auf den Rückwänden der Aufenthaltsräume stellt ein filigranes Architektur- oder Rankengestänge eine Feldergliederung her, die als solide, geschlossene ,Rückwand' für die Präsentation von Bildern diente ${ }^{16}$. Die Vorstellung eines dreidimensionalen, sich öffnenden Architekturraums wurde auf die Oberzonen beschränkt, nimmt aber eine luftig-irreale, ornamentale Gestalt an. Dies bedeutet, dass Innenraum und Außenraum stärker kontrastierend aufeinander bezogen wurden. Der Innenraum wurde zur geschlossenen Pinakothek, von der aus man in einen hellen, begrünten, offenen Außenraum blickte. Die Geschlossenheit der Wände wurde allerdings auf vielfältige Weise infrage gestellt. Das zentrale ,Tafelbild‘ der Mittelzone vermag dann, wenn es als Landschaftsbild aufgefasst ist, wie ein Ausblick in eine Landschaft zu

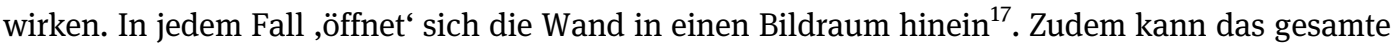
Wandsystem vegetabil durchdrungen sein: Pflanzen mögen vor der Sockelzone ,aus dem Boden` herauswachsen, Trägerelemente zu Pflanzenstängeln werden. Zwar ist die Wand geschlossen, doch die Natur hat sich ihrer bemächtigt. Eine klare Trennung zwischen Innenraum und Außenraum wird ad absurdum geführt. Diese Inversion konnte so weit führen, dass die Innenräume wie in den Cubicula (8) und (12) der Casa del Frutteto (I 9,5) als Gartenräume konzipiert wurden. Eine solche Raumgestaltung wählte man nicht nur für Räume, die sich auf das Peristyl öffneten - mit Cubiculum (8) erhält ein Cubiculum am Atrium einen solchen Garten-Decor (Abb. 330. 361). Die Erfahrung von Drinnen und Draußen ist hier vollständig invertiert: Ein geschlossenes, dunkles Cubiculum wurde durch seinen Decor als offenes Gartentriclinium imaginiert, das sich aber real auf einen geschlossenen Architekturraum öffnete. Gerade im dritten Stil sind daher Offenheit und Geschlossenheit, Enge und Weite noch einmal komplexer ineinander verschränkt, als dies bis dahin der Fall war.

Besonders weit geführt wurde dieses Spiel mit Drinnen und Draußen im späten dritten Stil. Im Tablinum (h) der Casa di Marcus Lucretius Fronto (Abb. 288-300) ist die Mittelzone der Wand zwar geschlossen, Kandelaber, Pinakes und Tafelbilder geben sich als Ausstattung eines Innenraums zu erkennen. Architekturdurchblicke werden jedoch als Trennglieder zwischen die Paneele eingefügt. Auf dem Sockel entfaltet sich vor einer opak-schwarzen Fläche eine filigrane Gartenlandschaft, mit der die opak-weiße Oberzone kontrastiert, die zum Hintergrund für eine filigrane Architektur wird. Schon die Behandlung der Wandflächen changiert somit zwischen Offenheit und Geschlossenheit. Ähnliches gilt für die Themenwahl. Nicht nur der Garten der Sockelzone und die Architekturen der Oberzone verweisen nach draußen, sondern auch die vier Landschaftspinakes auf den Seitenpaneelen der Mittelzone. Auf den mythologischen Mittelbildern wird einem Thiasos im Freien eine Innenraumszene gegenübergestellt, beide Bilder ,entführen' aber zugleich in eine mythische Welt. Im dritten, dann auch im vierten Stil wurden Offenheit und Geschlossenheit formal, medial und inhaltlich ineinander verschränkt.

Zusammenfassend zeigt sich, dass Offenheit und Geschlossenheit als Grundprinzipien jeder architektonischen Gliederung begriffen werden dürfen. Sie reflektieren, welche soziale Funktionen,

15 Morvillez 2018, 33f. mit einer (unvollständigen) Liste der entsprechenden Häuser in Pompeji - allerdings ohne konkrete Hinweise zur Datierung. Häufig tragen die Mauern Malereien im vierten Stil. Morvillez 2018, 36 zu Vorhängen, Verglasungen (nicht in Pompeji) und hölzernen Trennwänden.

16 Zur Neubewertung von Rahmen und Ornament im dritten Stil, s. jüngst Platt 2009, bes. 62f.

17 So auch Bergmann 2002, 33. 
aber auch welche ästhetischen Wirkungen von Architektur erwartet wurden. Die architektonischen Änderungen, die zwischen dem 2.Jh.v.Chr. und dem 1.Jh.n.Chr. greifbar werden, führten nicht zu einer immer stärkeren ,Öffnung ' des Hauses, vielmehr wurden Offenheit und Geschlossenheit in immer neuer Weise aufeinander bezogen. Die sich ebenfalls ändernden Decor-Formen ,reagierten auf die Architektur. Sie vermochten das architektonisch gegebene Konzept von Offenheit und Geschlossenheit zu stabilisieren, aber auch zu invertieren und zu labilisieren.

\section{3 Öffentlichkeit und Privatheit / Grandezza und Einfachheit: Raum und Decor}

Ausgehend von den Kategorien Offenheit/Geschlossenheit stellt sich die eingangs aufgeworfene Frage von Öffentlichkeit und Privatheit im römischen Wohnhaus und damit auch der sozialen Rezeption von Decor noch einmal neu.

Die vorausgegangenen Überlegungen haben ergeben, dass das Haus nach außen hin als abgeschlossene Einheit konzipiert und keineswegs ,frei` zugänglich war. Als das rückwärtige Peristyl im ausgehenden 2.Jh.v.Chr. als Wohnbereich etabliert wurde, wurde der interne' Bereich des Hauses auch von Gästen aufgesucht. Alle am Peristyl gelegenen Räume waren jedoch durch Türen verschließbar und konnten dem Zugang und Blick der Besucher entzogen werden. Auch ,Öffentlichkeit' und ,Privatheit' sind somit in komplexer Weise aufeinander bezogen.

Es ist damit nicht zu erwarten, dass Decor-Inhalte auf eine klar definierte Achse von Öffentlichkeit und Privatheit Bezug nehmen. Im ausgehenden 2. und beginnenden 1.Jh.v.Chr. besaßen Häuser nur wenige figürliche Bilder, die sich auf ihre räumliche Verteilung hin befragen lassen. Mit den dionysischen Kapitellen am Eingang wurde ein Thema für die ,Außenrepräsentation' gewählt, das luxuria und Lebensgenuss thematisiert. In der Casa del Fauno wurde dieses Themenfeld in seinen unterschiedlichsten Facetten im prunkvoll ausgestatteten Westatrium aufgegriffen ${ }^{18}$. Im Peristylbereich, wo man eine eher ,private Tonlage der Bildsprache erwarten würde, kam in der Alexander-Exedra indes ein Historienbild zur Darstellung. ,Privat‘ ist dieses militärisch-politische Bildthema jedoch nicht.

Mit dem zweiten Stil wurden dichte Bilderwelten vorzugsweise in jenen Aufenthaltsräumen entfaltet, von denen aus man auf ein Gartenareal oder in die Landschaft blickte. Der Bildkonsum ist damit jedoch keine ,private‘ Angelegenheit geworden, sondern war intensiven Rezeptionssituationen vorbehalten. Er war nur insofern sozial exklusiv, als nicht alle häuslichen Akteure daran partizipieren. Die Bildthemen selbst, die von Tier- über Landschafts- und Genredarstellungen bis hin zu mythologischen Bildern reichen, lassen sich auf keinen inhaltlichen Nenner bringen - etwa im Sinne einer ,privaten' Orchestrierung der Aufenthaltsräume. Vielmehr führten große Prunkräume wie der korinthische Oecus der Casa del Labirinto ausgesprochen komplexe Bilderwelten vor, die vielfältige Assoziationsmöglichkeiten eröffneten.

Im dritten Stil waren Bilder in allen Bereichen des Hauses gegenwärtig. Während allerdings in den offenen Hofbereichen dreidimensionale Bildobjekte inszeniert wurden und die Wandbilder mit ihren semantisch schwachen Motiven dahinter ,zurücktraten', avancierten die Aufenthaltsräume zu regelrechten ,Pinakotheken'. Noch immer lässt sich die Verteilung von Bildthemen jedoch nicht auf eine Achse von öffentlich und privat beziehen. Atrium und Peristyl erhielten durch die

18 So konstatiert auch Paul Zanker für die Atrien pompejanischer Häuser, dass ihr Decor nicht dem (von ihm dennoch angenommenen) halböffentlichen Charakter entspricht; Zanker 2000a, 208: „Wir können uns von den Atrien der großen Familien in republikanischer Zeit leider nur anhand der Schriftquellen eine Vorstellung machen, wo wir von rauchgeschwärzten Ahnenbildern, Beutewaffen und allen möglichen Zeugnissen des Ruhms und der Macht hören. Die erhaltenen Atrien in den Häusern von Pompeji aber sehen ganz anders aus, unterscheiden sich mit ihrem Bildschmuck kaum von den übrigen Räumen, das heißt, sie sind angefüllt mit Bildmotiven überwiegend erotischen und dionysischen Charakters, sie nehmen also nicht auf den halböffentlichen Charakter der Atrien Bezug.“ 
Einrichtung von Wasserspielen eine neue, sinnliche Qualität. Die Skulpturen nahmen auf dieses atmosphärische Setting Bezug. In den Atrien wurden verschiedentlich aufreizende Venusfiguren beim Bade präsentiert. In den Peristylen vermochte die heitere Otium-Atmosphäre durch den zur Verfügung stehenden Platz noch deutlich gesteigert zu werden: durch die Anlage von Gartentriclinia, prunkvollen Nymphäen und die Gestaltung regelrechter Skulpturengärten. Mit diesen sinnlichen Szenarien kontrastierten in beiden Höfen Formen der Selbstdarstellung - Porträthermen und Marmorbüsten. Schon in sich war das Ausstattungsspektrum der Höfe multivalent angelegt.

Der Unterschied zwischen Aufenthaltsräumen und Hofbereichen war in erster Linie ein medialer: Ikonographisch dichte Wandbilder waren den Aufenthaltsräumen vorbehalten. Am Beispiel der Casa di Giasone und der Casa di Marcus Lucretius Fronto zeigte sich, dass zwischen Tablinum und Cubicula oder zwischen einem zentralen Triclinium und seinen Nebenräumen die atmosphärische Grundstimmung der Bilder variiert werden konnte. Solche ,Modulierungen“ der Tonlage lassen sich insbesondere anhand der zentralen Mythenbilder fassen. In der Casa di Giasone fällt das ,royale‘ Iason-Bild in Triclinium (f) repräsentativer als die Variationen auf das Liebesthema in den Nebencubicula aus. In der Casa di Marcus Lucretius Fronto zeigten Tablinum (h) und Cubiculum (g) zwar gleichermaßen Paarbilder. Handelte es sich im Tablinum jedoch um repräsentative Konstellationen (Mars, Venus; Bacchus, Ariadne), wurden im Cubiculum nackte Körper vor den Augen des Betrachters entblößt. Die Mythenbilder des Cubiculums besitzen eine stärker erotisierende Tonlage $^{19}$. Mit einem Kampfbild über der Tür besitzt Cubiculum (g) allerdings auch eine Darstellung, die sich nicht in dieses Muster fügt.

Vor allem entziehen sich dieser Logik Räume mit nicht-mythologischen Bildthemen. So können in der Casa del Frutteto (I 9,5; Plan 7) das Cubiculum (8) am Atrium und jenes am Peristyl (12) gleichermaßen mit Gartenmalereien ausgestattet werden. Landschaftsbilder und ,Stillleben` kommen in offenen Räumen wie dem Tablinum der Casa di Marcus Lucretius Fronto vor, sie finden sich aber auch in geschlossenen Cubicula. Gerade die große Vielfalt an möglichen Bildoptionen erlaubt zwar auch eine Differenzierung in eher repräsentative und eher intime Bildinhalte, die auf entsprechend offene und geschlossene Räume verteilt werden können. Komplexe Bild-Ensembles lassen sich jedoch nicht auf diese Achse reduzieren. Die thematischen Anknüpfungspunkte erweisen sich als ähnlich komplex und divers wie das Handlungs- und Assoziationsspektrum, das man für Aufenthaltsräume erwarten darf.

Für die Zeit zwischen dem 2.Jh.v.Chr. und dem 1.Jh.n.Chr. scheint sich abzuzeichnen, dass Offenheit und Geschlossenheit und damit auch Öffentlichkeit und Privatheit sehr wohl als räumliche und soziale Kategorien bewusst waren. Decor-Inhalte setzten diese Oppositionen aber nicht linear um, sondern spielten mit der Einführung von Otium-Elementen in den besonders ,repräsentativ-öffentlichen' Bereich des Atriums wie auch mit der Inanspruchnahme des ,privaten' Peristyls als Repräsentationsraum. Offene Prunkräume (Tablina, Alae), große Aufenthaltsräume (Triclinia, Oeci) und Cubicula können ebenfalls durch ihren Decor aufeinander bezogen werden. Gerade die Bildervielfalt des dritten Stils eröffnet letztlich endlose Variationen.

\section{Symmetrie, Rhythmus und Axialität versus Variation}

Vitruv informiert uns für die augusteische Zeit über die große Bedeutung von Proportionen (eurythmia), Symmetrie (symmetria) und Rhythmus als architektonische Gestaltungsprinzipien ${ }^{20}$.

19 Ausführlich Lorenz 2008, bes. 431-442; für die Cubicula sind die Überlegungen etwa aufgegriffen bei Anguissola 2010, 314-339, die eine erotische und dionysische Aufladung der Cubicula ausmacht, aber auch auf Themen der intellektuellen und musischen Bildung verweist. Stillleben können zudem einen regelrechten Bankett-Luxus evozieren.

20 Vitr. 1,2,1: Architectura autem constat ex ordinatione, quae graece $\tau \alpha \xi\llcorner$ dicitur, et ex dispositione, hanc autem Graeci $\delta ı \alpha \vartheta \varepsilon \sigma \mathrm{v}$ vocitant, et eurythmia et symmetria et decore et distributione, quae graece oıкоvouı dicitur. Bei Vitr. 1,2,3-4 
In Privathäusern solle der Architekt den Grundriss gegebenenfalls an das zur Verfügung stehende Grundstück anpassen, um einen attraktiven Anblick (aspectus) zu gewährleisten (Vitr. 6,2,1):

Nulla architecto maior cura esse debet, nisi uti proportionibus ratae partis habeant aedificia rationum exactiones. Cum ergo constituta symmetriarum ratio fuerit et conmensus | ratiocinationibus explicati, tum etiam acuminis est prorprium providere ad naturam loci aut usum aut speciem <detractionibus aut> adiectionibus temperaturas <et> efficere, cum de symmetria sit detractum aut adiectum, uti id videatur recte esse | formatum in aspectuque nihil desideretur ${ }^{21}$.

Vitruvs Interesse an Symmetrie als Gestaltungskategorie hat den Blick der Forschung einseitig auf Regelhaftigkeiten, weniger auf Variationen und Abweichungen gelenkt ${ }^{22}$. Im Folgenden soll jedoch gerade die Spannung zwischen Symmetrie und Variation thematisiert werden - für die architektonische Gestaltung wie auch für den Decor.

Axialität und Parataxe und mit ihnen die Erzeugung von Rhythmus lassen sich als architektonische Gliederungsprinzipien für Hofbereiche beschreiben. Die Atrien samnitischer Häuser waren Prinzipien der Symmetrie unterworfen - mit der zentralen Achse von Fauces und Tablinum und der daran orientierten symmetrischen Platzierung von Cubicula. Wenn eine solche Ordnung aufgrund äußerer Beschränkungen nicht realisierbar war, so wurde Symmetrie mittels verschiedener Kunstgriffe hergestellt oder zumindest suggeriert. Bei einem unregelmäßigen Grundstückszuschnitt behielt man ein rechtwinkliges Atrium bei und verlegte die Asymmetrien in die Tabernae oder Cubicula hinein. War für symmetrisch angeordnete Cubicula kein Platz, so mochten Scheintüren einen entsprechenden Effekt suggerieren. Auch in regelhaft gestalteten Atrien hat man jedoch keine totale Symmetrie angestrebt. Die Alae waren üblicherweise nicht im Zentrum der Atriumsseiten platziert, sondern zum Tablinum hin versetzt. Dadurch erhielt das Atrium eine ,Wichtung‘. Zugleich ergab sich dadurch ein U-förmiges Arrangement der auf das Atrium gerichteten Prunkräume, die dadurch eine großformatige Tricliniums-Struktur bildeten. Dies dürfte mehr als eine formalistische Beobachtung sein: Bei großen Festen mag man Tablinum und Alae für die Aufstellung von Klinen genutzt und so die Räume funktional aufeinander bezogen haben. In kleineren Häusern hat man auf eine Symmetrieachse, die der Eingangsachse entsprach, bisweilen verzichtet, indem eine aus der Achse versetzte Ala als Hauptraum fungierte. Der Hofeindruck war in diesen Fällen durch eine asymmetrische Raumdisposition geprägt. Die in der Architektur angelegten Symmetrien und Asymmetrien wurden durch Decor-Elemente intensiviert. Am Atrium trugen die Stuckpilaster ersten Stils zur Inszenierung der Raumordnung bei, die Tessera-Reihen am Boden orientierten sich an der Ausrichtung der Wände und verstärkten das orthogonale Achsensystem. Die zentrale Achse (Fauces, Impluvium und Tablinum) wurde als Gliederungsachse inszeniert - in der Casa del Fauno etwa durch die Opera sectilia sowie durch die Platzierung der Faun-Skulptur

weiter ausgeführt: 3. Eurythmia est venusta species commodusque in compo/sitionibus membrorum aspectus. Haec efficitur, cum membra operis convenientia sunt altitudinis ad latitudinem, latitudinis ad longitudinem, et ad summam omnia respondent suae symmetriae. 4. Item symmetria est ex ipsius operis membris conveniens / consensus ex partibusque separatis ad universae figurae speciem ratae partis responsus. Uti in hominis corpore e cubito, pede, palmo, digito ceterisque particulis symmetros est eurythmiae qualitas, sic est in operum perfectionibus [...]; vgl. Bek 1980, 167-169, die davon ausgehend das Verhältnis von Symmetrieachsen und Sichtachsen diskutiert.

21 Übersetzung Fensterbusch: „Die größte Sorge des Baumeisters muß es sein, daß bei Privatgebäuden die Berechnung genau nach den Proportionen eines berechneten Teils (modulus) ausgeführt wird. Wenn also das System der Symmetrien bestimmt und die Symmetrien durch Berechnungen entwickelt sind, ist es auch Aufgabe eines verständigen Baumeisters, daß er dann im Hinblick auf die natürliche Beschaffenheit des Ortes oder die Verwendung oder das Aussehen durch Wegnahme oder Hinzufügen Milderungen vornimmt und bewirkt, daß, wenn von der Symmetrie etwas weggenommen oder ihr hinzugefügt ist, dies gehörig gestaltet zu sein scheint und beim Anblick nichts vermißt wird.“

22 Bei Ehrhardt 2012, 14 Symmetrie als ,Grundprinzip‘: „Symmetrischer Aufbau und Spiegelbildlichkeit bestimmen seit dem 2. Jahrhundert v. Chr., beginnend mit den frühesten kampanischen Wänäden Ersten Stils, die Gesamtdekorierung eines Zimmers.“ 
und des Tisches. Zisternenöffnungen konnten ebenfalls auf die Hausachse Bezug nehmen, wenn sie am vorderen oder hinteren Impluviumsrand eingesetzt waren. Die Arcae, vielleicht auch andere im Atrium aufgestellte Möbel, orientierten sich nicht an diesen Symmetriebeziehungen. Sie waren vor einem nicht durch Türen unterbrochenen Wandsegment aufgestellt und führten dadurch eine Asymmetrie in die Höfe ein. Ähnliches dürfte für Altäre bzw. Kultnischen gegolten haben.

Im Fall der Peristyle erzeugten nur auf allen vier Seiten umlaufende, im rechten Winkel platzierte Portiken den Eindruck von Symmetrie und Axialität. Pilaster an den Peristylwänden verstärkten die Wirkung. Bei dreiseitigen Peristylen verschob sich der Fokus auf die als Blickfang gestaltete Rückwand. In der Casa del Fauno befand sich die Nischenwand des Nordperistyls in der Achse des Hauses und betonte dadurch den axialen Aufbau des Hauses. Die Schauwand und die darauf bezogenen Haupträume konnten aber auch aus der Achse versetzt sein. Bei zweiseitigen Peristylen und Rumpfperistylen, die auf wenige Säulen beschränkt waren, ging der Eindruck von Regelhaftigkeit annähernd vollständig verloren. Die Abweichung von Symmetrieprinzipien kommt in den Peristylen zusätzlich dadurch zum Ausdruck, dass ihre Räume in relativ freier Abfolge platziert wurden.

Ein solches Spiel mit Symmetrie und Asymmetrie ergab sich auch in geschlossenen Räumen. Die Emblemata am Boden waren typischerweise auf die Mittelachse bezogen, in Tablina und Alae besetzten sie häufig die Raummitte. An der Wand erzeugten die Orthostaten und Quader hingegen eine parataktische Reihung und betonten die Horizontale. Axiale Symmetrien entstanden vor allem dann, wenn wie in den Fauces der Casa del Fauno der Wandstuck von sich gegenüberliegenden Wänden gespiegelt wurde. Die Betonung der Raumachsen am Boden konkurrierte folglich mit einer Wandorganisation, welche die horizontale Ausdehnung der Wand betonte und dabei rhythmisierte.

Ausstattungselemente konnten schließlich auch zu einer Wichtung des Raumes beitragen. In Cubicula konnten Emblemata im Vorraum platziert werden, in Triclinia auf die Aufstellung von Klinen reagieren ${ }^{23}$. Der Wand-Decor trug einer solchen Gliederung in Vorraum und Klinenbereich zunächst nur in Cubicula Rechnung. Gerade hier wurde Decor aber eingesetzt, um eine asymmetrische Nutzungsstruktur visuell zu verstärken.

Im mittleren 1.Jh.v.Chr. ergab sich durch die Platzierung von Wohnräumen am Peristyl ein zunehmend komplexes Spiel mit Symmetrien und Asymmetrien ${ }^{24}$. Dreiseitige Peristyle erlaubten die Inszenierung einer Schauwand, welche die Anlage von aus der Hauptachse versetzten Prunkräumen nach sich zog. Der axiale Blick durch das Haus verlor an Bedeutung zugunsten von Blickperspektiven, die sich von verschiedenen Wohnräumen aus ergaben. Dabei setzte man verstärkt auf Asymmetrien, um optische Variationen einführen zu können. In Cubiculum (42) der Casa del Labirinto war die rückwärtige Kline nicht mittig, sondern versetzt platziert, um einen möglichst axialen Blick in den Hof zu gewährleisten. Überhaupt schätzte man nun Cubicula mit über Eck aufgestellten Klinen.

Am Boden ging die Tendenz hin zu einer stärkeren Akzentuierung des Raumes. Für Alae und Tablina bedeutete dies die Betonung des Raumzentrums und der Schwellen. Triclinia und Oeci konnten ,symmetrisch“-einheitlich entworfen, durch ihren Decor aber auch in Vorraum und Hauptraum gegliedert werden. Für Cubicula wurde eine asymmetrische Gliederung, die zwischen Vorraum und Klinenbereich unterschied, besonders beliebt. Dabei verzichtete man mit den Schwarz-

23 Jung 1984, 90; Horrocks 2000, 39-41 thematisieren solche Binnenperspektiven auf den Raum als „composed views“. Der bevorzugte Aufenthaltsort innerhalb eines Raumes sei auf ein Bild bezogen. Tatsächlich nehmen sich die Blickbeziehungen auch innerhalb von Räumen komplexer aus und verändern sich durch verschiedene Decor-Strategien im Laufe der Zeit.

24 Überlegungen zur freieren Disposition der architektonischen Elemente in der späten Republik und frühen Kaiserzeit bei Bek 1980, 184-186. 
Weiß-Mosaiken zusehends auf Bilder, die auf eine Betrachterperspektive festgelegt waren. Der Decor am Boden wurde in jeder Hinsicht ,abstrakt".

An den Wänden hingegen verbanden sich eine axiale Raumorganisation und eine stärkere Ausrichtung auf Betrachterperspektiven. Die gemalten Säulenarchitekturen erlaubten erstmals eine vertikale Gliederung und damit auch eine axialsymmetrische Strukturierung der Wand. Dieses Prinzip wurde grundsätzlich auf der Rückwand eines Raumes entfaltet - jener Wand also, auf die der Eintretende blickte. Auf den Seitenwänden kam es jedoch zu Modifikationen. In einem Raum wie dem korinthischen Oecus, der nicht in Vorraum und Klinenbereich untergliedert war, betonte die axialsymmetrisch organisierte Wandmalerei zwar das ungefähre Wandzentrum. Die Ausrichtung der Wandbilder auf spezifische Betrachterstandpunkte und insbesondere auf die Blickoptionen, die sich von der Kline summus in imo ergaben, führte jedoch zu neuen Asymmetrien. Um die Betrachterperspektiven in optimaler Weise zu bedienen, ist das Zentrum der Wandmalerei im korinthischen Oecus leicht aus der Querachse versetzt und verhält sich dadurch zugleich asymmetrisch zu den realen Säulen (Abb. 154. 161). Die Architekturillusionen des zweiten Stils nehmen folglich Asymmetrien, die sich durch verschiedene Blickpunkte ergeben, gezielt in Kauf.

Mit dem Übergang zur Kaiserzeit wurden Betrachterorientierung und Symmetrisierung in komplexer Weise miteinander verhandelt. Um für die rückwärtige Kline eine attraktive, möglichst symmetrische Perspektive auf den Garten zu erreichen, wurden die Haupträume im Verhältnis zum Hof bisweilen leicht dezentral platziert. Mit der Asymmetrie ging ein Zugewinn an Intimität einher. Die gegenüberliegenden Peristylrückwände wurden aufwendig gestaltet, z.B. mit Nymphäen, Schaunischen oder Gartenmegalographien. Gleichzeitig wurde die Ansicht auf die Peristylhöfe stärker bildhaft konzipiert, die Höfe dadurch einer strengeren Symmetrisierung unterworfen. Die Hofansichten waren nicht auf einen bestimmten Standpunkt hin entworfen, sondern ,abstrakt" aus dem Grundriss heraus entwickelt. Dies gilt für die Anlage von Dreiraumgruppen wie jener am Atrium-Peristyl der Casa di Giasone (Abb. 263; Plan 3), aber auch für Raumpendants wie jenem im südlichen Garten (32) der Casa di Sallustio (VI 2,4; Abb. 320). Dadurch waren die Raumsymmetrien nicht von Orten aus zu erfassen, die für ein längeres Verweilen vorgesehen waren, sondern erschlossen sich dem in den Hof Eintreten en passant.

Eine streng symmetrische Decor-Struktur ist nun auch für die Raumausstattungen zu greifen. Das Wandbild wurde nicht mehr wie im zweiten Stil auf verschiedene Perspektiven hin entfaltet, sondern folgte einem abstrakten, axialsymmetrischen Gliederungsprinzip ${ }^{25}$. Der neue, theoretisch konzipierte Decor-Raum verlangte dem Betrachter eine stärkere Abstraktion der Seherfahrung ab. Am Boden wurde das Paviment durch einen Randstreifen in systematischerer Weise zum Grundriss und damit auch zur Wand in Beziehung gesetzt.

Für den gesamten Untersuchungszeitraum sind Symmetrien und der gezielte Bruch mit Symmetrien für die Gestaltung von Decor-Räumen zentral. Während Symmetrien eine rasche Orientierung im Raum erlauben, ermöglichen Asymmetrien die Einführung von Variationen und Überraschungseffekten. Symmetrien beziehen sich auf ein abstraktes Konzept, während die Rücksichtnahme auf verschiedene, konkurrierende Betrachterhaltungen zu Asymmetrien führt.

25 Zur stärkeren Abstraktion bereits Wesenberg 1985, 486; diese Beobachtung hat m. E. nichts mit einer Wertung zu tun (anders Schmaltz 1989, 220f.). 


\section{Zentralität und Liminalität: die Gestaltung von Übergängen}

In der Realisierung von Axialsymmetrien sind Zentrum und Peripherie immer schon mitgedacht. Compluvium und Impluvium besetzen das Zentrum des Atriums, der Gartenbereich das Zentrum des Peristyls. Prunkpavimente des ersten Stils machen die Raummitte zum optischen Gravitationszentrum. Im zweiten und dritten Stil wird die axiale Wandmitte besonders hervorgehoben, innerhalb eines Raumes liegt der Fokus auf der ,mittigen' Rückwand.

Im Folgenden gilt es, solche Phänomene der Zentralität in ihrem Verhältnis zur Liminalität zu bestimmen. Tatsächlich wurde Decor zuvorderst zur Betonung der liminalen Zonen eingesetzt: Böden, Wände und Decken lassen sich als ,Rahmung‘ eines dreidimensionalen Raumvolumens, als Begrenzung der im Raum stattfindenden Handlungen begreifen. Da man insbesondere diese Raumbegrenzungen mit Decor besetzte, wurden diese zu einem Interface, das für die Interaktionen im Raum höchst bedeutsam war. Dieses Interface wurde mit realen Öffnungen, Türen und Fenstern versehen. Der Blick aus dem Raum hinaus wurde entsprechend durch Fenster- und Türeinfassungen gerahmt. Solche ,gerahmten' Blicke wurden mit dem 1.Jh.v. Chr. immer bedeutsamer.

Zentralität und Liminalität lassen sich darüber hinaus in Bezug auf einzelne Bauglieder bestimmen. Wieder sind es Zonen des Übergangs, die durch Decor besonders akzentuiert wurden. An Stützelementen (Säulen, Pfeiler) trifft dies auf Basen und Kapitelle zu. Im aufgehenden Mauerwerk ist der Übergang zwischen Wand und Dach durch verschiedene Fries- und Ornamentzonen besetzt, am Dach wird die Sima mit besonderem gestalterischem Aufwand belegt. Es gilt aber auch für Decor-Elemente, welche die Architekturordnung orchestrieren - die Pilasterrahmungen der ganz auf die Höfe geöffneten Haupträume etwa.

Der Decor intensiviert somit die Aufmerksamkeit für die ohnehin ,auffälligen` Übergangszonen $^{26}$. Dies führt dazu, dass der Betrachterblick zwischen der Wahrnehmung des Rahmens und des Gerahmten oszilliert, beides bedingt sich gegenseitig ${ }^{27}$. Rahmen sind jedoch nicht nur ein Phänomen von Architektur-Ordnungen, sondern auch von Decor-Ordnungen ${ }^{28}$. Mit anderen Worten spielt bei der internen Organisation von Decor-Systemen die Gestaltung von Übergangszonen eine wichtige Rolle.

Der erste Stil, der auf den Aufbau einer realen Wand bezogen ist, trennt die einzelnen Wandzonen durch Profilleisten, die eine besondere Ornamentierung erfahren können. Dies gilt für den Gurt, der Sockel- und Orthostatenzone voneinander schied und in den Fauces der Casa del Fauno zum Träger eines perspektivischen Mäanders wurde (Abb. 8). Auch der Übergang zwischen Orthostaten- und Quaderzone kann besonders gestaltet sein. Im Atrium der Casa di Sallustio befindet sich an dieser Stelle eine farblich auffällige, violette, profilierte Leiste (Abb. 94). Andernorts tritt dieser Bereich plastisch hervor, wird durch eine Läufer-Binder-Reihe strukturiert oder sogar zum Träger von Bildelementen. In besonderer Weise akzentuiert ist schließlich der Übergang zwischen Mittelzone und Oberzone der Wand. Im Tablinum der Casa di Sallustio befindet sich an dieser Stelle ein gemalter, vegetabiler Fries, darauf folgt das durch seine Plastizität ohnehin besonders herausgehobene Epistyl (Abb. 113). Bezeichnenderweise wird Figürlichkeit und Gegenständlichkeit gerade in diesen liminalen Zonen entfaltet. Darüber hinaus arbeitet der erste Stil mit noch kleinteiligeren Rahmenelementen. Die Stuckquader werden durch einen zurückgesetzten

26 Gombrich 2002, 121 Abb. 132 zeigt über die Messung von Augenbewegungen auf, dass Fixationspunkte bei der Wahrnehmung von Säulen und Gebälk vor allem im Bereich der Übergangszonen liegen.

27 Jones 2019, $47 \mathrm{f}$.

28 Zum Rahmen: Beyer 2008, bes. 19: Sie begreift Rahmen in Rückgriff auf Louis Marin als dreifach bestimmtes Intervall - als Intervall zwischen dem Bildraum, der Bildoberfläche und dem Raum der Repräsentation; Platt - Squire $2017 \mathrm{zu}$ verschiedenen Funktionen von Rahmungen; ihre Überlegungen zur römischen Wandmalerei bleiben jedoch sehr allgemein. 
Randschlag ,gerahmt‘. In der Orthostatenzone kann ein farblich anders gefasster, ,echter` Rahmenstreifen hinzutreten. Das Architekturglied der Orthostaten wird dadurch regelrecht bildhaft aufgefasst. Dieser Eindruck verstärkt sich, wenn die großen Platten zum Träger von figürlichen Malereien werden.

Rahmenelemente sind an der Wende vom 2. zum 1.Jh.v.Chr. auch für die Bodengestaltung bedeutsam. Kostbare Mosaikemblemata sind nicht selten von Prunkrahmen eingefasst. So wird in der Casa del Fauno der aggressive Löwe in Triclinium (30/42) von einem perspektivischen Mäander ,umhegt‘ (Abb. 56), der auf einem Tiger-Löwen reitende Bacchus-Amor von Triclinium (14/34) von einer prunkvollen Festgirlande mit Blättern, Blüten, Früchten und Masken umrankt (Abb. 24), zu der zusätzlich ein laufender Hund hinzutritt, während das Fischmosaik in Triclinium (12/35) von einem opulenten Blatt- und Blütenfries umgeben ist (Abb. 23). Der große Aufwand, der für die Rahmungen betrieben wird, lenkt die Aufmerksamkeit vom eigentlichen Hauptbild ab. Zugleich leistet der Prunkrahmen aber auch eine Aufwertung der Mittelbilder. Der Blick gerät in Bewegung, ,springt' zwischen Rahmung und Bild. Daneben findet sich in den Alae der Casa del Fauno auch ein anderer Umgang mit Rahmungen. Die sehr viel kleineren Mosaikemblemata sind von schmalen Rahmenlinien eingefasst, die ganz hinter dem Bildfeld zurücktreten (Abb. 19. 21). Die Rahmenlinie nimmt auf das kleine Format der Bilder Rücksicht.

Mit der malerischen Realisierung von Architektur liegt im zweiten Stil die Aufmerksamkeit auf jenen Übergangsbereichen, die auch in der gebauten Architektur mit besonderer Decor-Intensität belegt werden - nämlich dem verkröpften Podium und Gebälk, auf Säulenbasen, Kapitellen und Architekturfriesen. Diese Zonen werden durch besondere Materialien aufgewertet, aber auch zum Träger von figürlichen Darstellungen. Mit der Einführung von Säulen und Pfeilern als vertikalen Gliederungselementen ist darüber hinaus die Möglichkeit gegeben, Architektur selbst als Rahmung aufzufassen: als Rahmung für Bildelemente, Skulpturen, Objekte und menschliche Figuren, die in die Architektur Eingang finden, aber auch als Rahmung von Ausblicken auf andere Architekturen ${ }^{29}$. Wie sich die einzelnen Elemente - Architekturen, Durchblicke, Bilder und Objekte - zueinander verhalten, fällt von Wand zu Wand unterschiedlich aus. Hier sollen nur noch einmal einzelne wenige Kontexte in Bezug auf die Qualität von ,Rahmungen“ in Erinnerung gerufen werden. Wenn wie auf den Seitenwänden des korinthischen Oecus der Casa del Labirinto eine spektakuläre Prunkarchitektur entfaltet wird, durch die hindurch man auf andere Baukomplexe blickt, wird die gesamte Wand als Architekturraum präsentiert (Abb. 153-158). Indem die Schauarchitektur Gesetzen der Axialität und Symmetrie folgt, wird die Architektur nach Kategorien von Zentrum und Rahmung organisiert. Die Wand gewinnt dadurch an Übersichtlichkeit und Komplexität zugleich. Im benachbarten Cubiculum (42) kommt der ,Rahmenarchitektur‘ eine noch prominentere Rolle zu. Die Gebälkstützen nehmen die Gestalt von ,monumentalen', auf Schiffen stehenden Seekentauren an (Abb. 164. 166). Die besondere Beliebtheit figürlicher Stützen (,Hermen'/Karyatiden) im zweiten Stil ist sicher auch darin begründet, dass sich in ihnen die Inszenierung einer bildlich konzipierten Skulptur und einer Rahmung überschneiden ${ }^{30}$. So fassen die Hermen in der Kryptoportikus der Casa del Criptoportico (I 6,2) Felder ein, die - von herabhängenden Ranken abgesehen - leer bleiben (Abb. 203-205). Die Architektur kann schließlich ihrerseits zur Bühne für die Präsentation von Bildobjekten werden. Insbesondere bei Bild-Objekten, die in Bezug auf die Architektur präsentiert werden, findet der zweite Stil unterschiedliche Optionen, Bildlichkeit und Rahmung zu ,plausibilisieren'.

Mit dem dritten Stil wird ,Architektur' an der Wand in ganz erheblichem Umfang ,labilisiert‘. Hatte sich der zweite Stil dadurch ausgezeichnet, dass Architekturen und Bilder in ständiger Konkurrenz zueinander standen, führt die Rücknahme an Plastizität nun dazu, dass Architekturen

29 Allgemein (ohne Bezug auf einen spezifischen Wandmalerei-Stil), s. Platt - Squire 2017a, 66: „Roman mural schemes consequently frame the viewer in a variety of different ways, refusing any straightforward distinction between frame and content, ornament and work, or even figure and ground: while they delineate and circumscribe any number of framed entities - from painted vistas to fictional pinakes - these entities are themselves nothing but frames.“

$30 \mathrm{Zu}$ den Erechtheion-Koren, s. Platt - Squire 2017, $54 \mathrm{f}$. 
noch stärker als Rahmenornament wahrgenommen werden. Sie treten hinter der Präsentation von Bildern zurück. Es sind jedoch erhebliche Unterschiede denkbar. Im schwarzen Cubiculum (15) der Villa des Agrippa Postumus entfaltet die filigrane, goldene Architektur auf schwarzem Grund eine auffällige Wirkung, zumal die Landschaftsvignetten in ihrer Inszenierung zurückgenommen sind (Abb. 371). Im benachbarten roten Cubiculum (16) hingegen rahmt die Architektur große Bilder, die sich ,in den Vordergrund“ spielen. Grundsätzlich ist die Labilisierung und Ornamentalisierung der Architektur im frühen dritten Stil besonders weit getrieben, während sie am Übergang zum vierten Stil erneut an Volumen und Dreidimensionalität gewinnt. Im Tablinum (h) der Casa di Marcus Lucretius Fronto werden in der Mittelzone die Bildfelder durch illusionistische Architekturdurchblicke voneinander getrennt, die ihrerseits eine Rahmung durch eine Blütenranke erhalten haben (Abb. 288. 292). Der ,rahmende“ Architekturdurchblick wird somit seinerseits zum Bild. Vor allem aber sind Bildelemente in diesem Raum derart verdichtet, dass sie nicht nur das Wandzentrum, sondern auch ,Rahmenzonen' besetzen - den Sockel, die Predella und die Oberzone. Sie unterliegen zwar einer visuellen Hierarchisierung, doch treten Haupt- und Nebenzonen in eine permanente Konkurrenz zueinander. Richtet sich die Wahrnehmung auf ein Einzelbild, tritt das decorative System in der Wahrnehmung zurück. Hat man das gesamte Wandbild im Blick, so erhalten die einzelnen Bilder in der Wahrnehmung eine ornamentale Qualität.

Während in der gebauten Architektur liminale Zonen den Übergang zwischen unterschiedlichen Raumqualitäten (etwa vom Atrium zum Peristyl) markieren und am architektonischen Einzelglied verschiedene Funktionsbereiche geschieden werden (etwa Tragen und Lasten), so können malerisch-imaginierte Rahmungen unterschiedliche Modi der Repräsentation voneinander scheiden. Der erste Stil experimentiert mit einer solchen Differenzierung in den figürlichen Friesen, die als separat wahrnehmbare Bild-Bänder in die Architektur eingeführt werden und damit einem anderen Repräsentationsmodus als die Wand verpflichtet sind. Der zweite Stil folgt dem ersten Stil in der Konkretheit der Architekturauffassung. Die repräsentierte Architektur wird als konkreter Rahmen für die Präsentation von Bildern, Skulpturen, Objekten, Tieren und Menschen eingeführt. Allerdings wird der ,Realitäts-Status‘ dieser Elemente zugleich infrage gestellt. Darstellungen changieren zwischen Bild und Ausblick; ein Fries kann die Position eines Architekturfrieses einnehmen, aber auch als Bildfries erscheinen; Bildfiguren sind als Skulptur und Mensch wahrnehmbar. Im zweiten Stil treten zudem die ersten, mit einem eigenen Rahmen versehenen Bilder auf. Es sind gerahmte Pinakes wie in Cubiculum (46) der Casa del Labirinto (Abb. 171. 176) oder Klapptürbilder wie im Oecus (22) der Casa del Criptoportico (I 6,2; Abb. 207). Die Bildrahmung führt einen anderen Modus des ,Sprechens‘ ein, zeigt Fiktionalität an. Allerdings sind Pinakes immer auch als konkrete Bildobjekte im Raum, die Klapptürbilder als Fensterausblicke verständlich. Im dritten Stil wird mit den verschiedenen Optionen von Rahmung und Nicht-Rahmung gezielt gespielt. Allein komplexe Mythenbilder erhalten durchgängig einen Rahmen, werden zudem im Wandzentrum und in respektabler Größe präsentiert, ziehen Aufmerksamkeit auf sich, werden zu gerahmten Tafelbildern. Für alle anderen Sujets - für Landschaftsbilder ebenso wie für ,Stillleben' und Einzelmotive - ist eine Präsentation als gerahmtes Bild wie als rahmenlose ,Vignette‘ möglich. Die Rahmung stellt eine Option der visuellen Aufwertung dar. Da diese Strategie jedoch nicht nur für ikonographisch dichte, groß dargestellte Sujets eingesetzt wird, sondern auch für isolierte und zudem kleinteilige Einzelmotive und in die Architekturen eingestellte Bildobjekte (wie Kandelaber), macht die Rahmung das Dargestellte noch nicht zum Bild. Umgekehrt können rahmenlose Vignetten im Wandzentrum ,aus der Wand heraustreten', als Bild ,erscheinen', sich von ihrer Umgebung dadurch ,abheben ${ }^{31}$. Es braucht den Rahmen nicht als Anzeiger für eine ikonische Differenz, und umgekehrt macht die Rahmung ein ornamenthaftes Sujet noch nicht zum Bild. Der Wand-Decor des dritten Stils zielt auf die Inszenierung solcher Ambiguitäten.

31 Platt - Squire 2017a, bes. $24 \mathrm{f}$. 


\section{Raumvolumina und Decor-Größen}

Über die verschiedenen Stile hinweg lässt sich beobachten, dass das decorative System an die Raumproportionen angepasst wird, um die Architektur durch adäquate Decor-Proportionen in Szene zu setzen. Proportion (bei Vitruv ordinatio ${ }^{32}$ ) bestätigt sich darin als zentrales Gestaltungsprinzip.

Im ersten Stil bedeutet dies, dass für große Räume, insbesondere für Hofbereiche, ein großer, für kleine ein reduzierter Decor-Maßstab gewählt wird. Dies gilt für Atrien im Verhältnis zu Cubicula, innerhalb der Cubicula für den Decor-Maßstab in Vorraum und Alkoven. Allerdings können einzelne Decor-Elemente dieses Decor-Prinzip invertieren. In der großen Alexander-Exedra mit ihren großflächigen Orthostaten und Quadern fällt die Malerei auf den Quadern kleinteilig aus und fordert eine Betrachtung aus der Nähe ein. Ähnliches gilt für den Girlandenfries im Tablinum der Casa di Sallustio (VI 2,4; Abb. 113). Umgekehrt fällt der gemalte Fransenschal im Alkoven von Cubiculum (15) der Casa dei Quattro Stili (I 8,17) relational betrachtet auffällig groß aus (Abb. 88). Gerade Bildelemente vermögen die Aufmerksamkeit auf sich zu ziehen und eine veränderte Betrachterhaltung zu erzeugen. In noch expliziterer Weise gilt dies für figürliche Mosaikemblemata am Boden. Sie ziehen aufgrund ihrer mittigen Platzierung, ihrer Rahmung, aber auch aufgrund ihrer Polychromie und ihrer ikonographischen Dichte die besondere Aufmerksamkeit der Betrachter auf sich. In ähnlich großen Räumen konnten jedoch ganz unterschiedliche Emblema-Größen zum Einsatz kommen. In den Alae der Casa del Fauno verwendete man kleine, pinaxartige Bildfelder mit schmaler Rahmenlinie (Abb. 19. 21), die benachbarten Triclinia besitzen raumgreifende Mittelbilder mit aufwendigen Prunkrahmen (Abb. 23. 24. 56), während in der Alexander-Exedra nahezu der gesamte Boden von einem Bild ausgefüllt wird, das den Raum gänzlich dominiert (Abb. 43). Je nach Emblema-Größe ergeben sich sehr unterschiedliche Betrachterhaltungen.

Im zweiten Stil werden die beiden schon zuvor wirksamen Formen der visuellen Differenzierung an der Wand noch klarer unterscheidbar: der visuelle Detailreichtum einerseits, die Größenskala des Decors andererseits. Sowohl die prunkvollen, detailreich formulierten, geöffneten Scheinarchitekturen als auch die geschlossenen und großflächiger wirkenden Architekturen können in großem wie in kleinem Maßstab vorgeführt werden. Mit der Variation der Decor-Größen ergeben sich jedoch gänzlich unterschiedliche Effekte. In großen Aufenthaltsräumen wie dem korinthischen Oecus der Casa del Labirinto erzeugen prunkvolle Scheinarchitekturen durch ihren großen Maßstab einen geradezu ,royalen` Kontext, während das benachbarte, kleine Cubiculum (46) durch seine Miniaturarchitektur einen besonders intimen, aber auch kostbaren Charakter erhält. Geschlossene Architekturprospekte machen die großen Atrien und Peristyle übersichtlich und erlauben eine rasche Orientierung. Kommen sie in kleinen Cubicula zum Einsatz, so erscheinen diese - ähnlich wie die Cubicula des ersten Stils - als kostbar ausgestattete Innenräume. In den kleinen Räumen nimmt der kleine Decor-Maßstab auf die nahsichtige Betrachtung Rücksicht, in großen Höfen suggeriert er Grandezza.

Im dritten Stil erweitern sich die Optionen zur visuellen Differenzierung von Räumen noch einmal. Die grundsätzliche Idee, den Decor-Maßstab an die Raumgröße anzupassen, wird jedoch beibehalten. Große Räume besitzen in der Tendenz große Orthostaten - und mit diesen auch große Mittelbilder -, kleine Räume hingegen kleine Orthostaten und kleine Mittelbilder. Im Prunk-Oecus (19) der Casa del Citarista (I 4,5.6.25.28; Plan 5) führt dies zu riesigen mythologischen Mittelbildern, die es möglich machen, dass man selbst ikonographische Details von annähernd allen Positionen im Raum aus erkennen konnte. Im benachbarten, kleinen Cubiculum (23) hingegen fordern die kleinen quadratischen Bildfelder eine Nahsicht ein und erzeugen dadurch eine intime Raumwirkung. Zu den Mittelbildern treten im dritten Stil jedoch zahlreiche weitere Decor-Elemente unterschiedlicher Größe und Komplexität hinzu, welche die Sockelzonen, die Seitenfelder der Mittelzonen und Oberzonen besetzen. Auf diese Weise kann sich in ein und demselben Raum ein Spiel mit Ferne und Nähe, Größe und Kleinteiligkeit, entfalten.

32 Vitr. 1,2,2. 


\section{Licht und Farbe}

Die Wahrnehmungen von Licht und Farben korrelieren miteinander ${ }^{33}$. Mit dem Wandel von Architektur und Decor-Formen nimmt sich jedoch auch dieses Korrelat immer wieder anders aus.

Die Helligkeit häuslicher Räume hängt einerseits von der Größe und Breite ihrer Tür- und Fensteröffnungen ab, andererseits von ihrer Orientierung nach den Himmelsrichtungen. Vitruv formuliert konkrete Empfehlungen für die Ausrichtung von Funktionsräumen ${ }^{34}$, allerdings ist diese wenigstens zum Teil durch die Orientierung der Hausgrundstücke auf einer Insula bestimmt und kann daher nicht ausschließlich als Ausdruck eines Gestaltungswillens interpretiert werden. Da die Hauseingänge üblicherweise auf große Straßen ausgerichtet waren, gilt allgemein, dass die Häuser auf der Nordseite der Via dell'Abondanza nach Süden, jene auf der Südseite der Via dell'Abbondanza nach Norden geöffnet waren, jene auf der Westseite der Via Stabiana nach Osten und auf der Ostseite der Stabiana nach Westen. Die weitläufige Casa del Citarista (I 4,5.6.25.28; Plan 5), die am Schnittpunkt der beiden Achsen liegt, verfügt über Hausteile unterschiedlicher Orientierung. Für die Aufenthaltsräume, für deren Ausrichtung Vitruv besonders umfängliche Empfehlungen gibt, bedeutet dies, dass sie bei Nord-Süd-orientierten Grundstücken häufig nach Norden oder Süden geöffnet waren, bei Ost-West orientierten Grundstücken dementsprechend nach Westen oder Osten. Die Farb- und Materialqualitäten von Boden-, Wand- und Decken-Decor entfalten sich wiederum in Abhängigkeit von der natürlichen (und künstlichen) ${ }^{35}$ Beleuchtung eines Raumes.

Die Lichtverhältnisse in den Höfen änderten sich zwischen dem 2.Jh.v.Chr. und dem 1.Jh.n.Chr. nicht grundlegend. Tuskanische und tetrastyle Atrien erhielten ihr Licht mittig über eine verhältnismäßig kleine Compluviumsöffnung, sodass die Räume typischerweise durch ein Halbdunkel geprägt waren. Heller fielen vielsäulige Atrien mit großer Compluviumsöffnung aus, wie jenes der Casa di M. Epidius Rufus (IX 1,20; Plan 20). Ihre Lichtqualitäten näherten sich einem Peristyl an. Neben der Dachöffnung erhielten Atrien indirektes Licht über die Tür- und Fensteröffnungen der angrenzenden Räume. Über die schmalen und tiefen Fauces gelangte allerdings kaum Licht in den Hof selbst. Eine Ausnahme bildeten Häuser, deren Zugang im Westen lag, sodass im Spätsommer und Herbst die tief stehende Nachmittagssonne bei geöffneten Türen annähernd horizontal einfallen konnte. Eine weitere, indirekte Lichtquelle stellte die rückwärtige Tablinumsöffnung dar. Die frühen Tablina wie jenes der Casa del Fauno besaßen üblicherweise ein großes, durch Läden verschließbares Fenster. Im Verlauf des 1.Jhs.v.Chr. entschied man sich immer häufiger für eine vollständige (jedoch auch durch Türen verschließbare) Öffnung des Tablinums zum rückwärtigen Peristyl, wodurch das Tablinum selbst wie das Atrium etwas heller wurde ${ }^{36}$. Besaßen Häuser kein axial platziertes Tablinum, sondern eine um 90 Grad versetzte, als Tablinum fungierende Ala wie die Domus VI 2,11, so fiel diese Lichtquelle weg. Selten verfügten auch die Alae wie in der Casa di Sallustio (VI 2,4) über rückwärtige Außenfenster und führten dem Atrium dadurch zusätzlich Licht zu (Abb. 117). Die Gestaltung der Alae und Tablina hatte somit einen gewissen Einfluss auf die Lichtsituation im Atrium. Die verschließbaren Cubicula erhielten über

33 Grüner 2014, 424f. mit dem Hinweis, dass die Oberflächenwirkung durch Farbwerte und Helligkeitswerte bestimmt ist. Material und Glanz, die ein weiteres analytisches Paar darstellen würden, sind hier ausgelassen, da bislang nur sporadische Überlegungen zum Glanz in der Wandmalerei vorliegen.

34 Vitr. 6,4. Für Winter-Triclinia und Baderäume empfiehl er eine Ausrichtung nach Westen (occidentem hibernum), damit sie von der Abendsonne profitieren; für Cubicula und Bibliotheken sei eine Ausrichtung nach Osten günstig, weil dies nicht nur für ihren Gebrauch notwendig sei, sondern auch die Bücher vor Feuchtigkeit schütze. Für Frühlings- und Herbst-Triclinia empfiehlt er ebenfalls eine Ausrichtung nach Osten, während die Sommer-Triclinia nach Norden ausgerichtet sein sollten.

35 Die künstliche Beleuchtung wird im Folgenden nicht in Rechnung gestellt, weil die Zahl und Platzierung von künstlichen Lichtquellen nur spekulativ erschlossen werden kann.

36 Die von Schmaltz 1989, 222f. für das Tablinum der Casa di Marcus Lucretius Fronto postulierte Dunkelheit, die eine Betrachtung der Oberzonen erschwert hätte, ist für mich vor Ort nicht nachvollziehbar. Auch heute müssten, mit rekonstruiertem Dach, die Lichtverhältnisse ungefähr denen der Antike entsprochen haben. 
das Atrium nur wenig Licht. Mit ihren kleinen, hoch angebrachten Fenstern und schmalen, üblicherweise wohl geschlossenen Türen waren sie dunkel und dürften vornehmlich über künstliches Licht erhellt gewesen sein.

Anders nimmt sich die Situation am Peristyl aus. Von den vierseitigen Portiken, welche die Gärten einfassen, lag je nach Sonnenstand wenigstens ein Portikusflügel ganz im Schatten, ein anderer vollständig in der Sonne. Fiel die Sonne auf einen der Peristylflügel, so warfen die Peristylsäulen Schatten in den Peristylumgang und rhythmisierten dadurch die Bewegung zusätzlich. In Rumpfperistylen waren die Lichtverhältnisse von der Ausrichtung der Portiken abhängig. Grundsätzlich aber waren die Peristylflügel durch die große Hoföffnung hell.

Die Wohnräume am Peristyl erhielten meist kein direktes Sonnenlicht, da ihnen Portiken vorgelagert waren. In Räume, die nach Osten, Süden oder Westen orientiert waren, konnte jedoch die auf- bzw. untergehende Sonne sowie die tief stehende Wintersonne einfallen und diese mit Licht und Wärme versorgen. Der Zuschnitt von Raum- und Fensteröffnungen solcher direkt am Peristyl gelegener Räume veränderte sich, wie gesehen, zwischen dem 2. und 1.Jh.v.Chr. deutlich. An die Stelle von ganz auf den Hof geöffneten Exedren traten im Verlauf des 1.Jhs.v. Chr. kleine wie große Räume mit breiten, jedoch durch Türen verschließbaren Raumöffnungen. In augusteischer Zeit wurden die Raumqualitäten ins Extreme gesteigert: Auf dem einen Ende der Skala standen nun riesige Prunkräume mit enormem Raumvolumen und weiten Durchgängen, auf dem anderen Ende der Skala kleine Diaetae, die mit proportional großen Fenstern und breiten Türöffnungen versehen waren. Es waren somit insbesondere die am Peristyl gelegenen Aufenthaltsräume, deren Lichtqualitäten im Laufe der Zeit einem Wandel unterlagen.

In Bezug auf diese Lichtverhältnisse sind im Folgenden die Farb- und Materialqualitäten von Böden, Wänden und Decken zu beurteilen. Hier sind letztlich endlos viele Gestaltungsoptionen denkbar, sodass nur einzelne Aspekte und Tendenzen herausgegriffen werden können.

Im späten 2. und beginnenden 1.Jh.v.Chr. haben Atrien und Peristyle des ersten Stils üblicherweise einen dunklen, d.h. schwarzen oder roten Estrichboden (Lavapesta; Cocciopesto) erhalten, in Sonderfällen wie der Casa del Fauno konnte im Peristyl auch ein polychromes Lithostroton eingebracht werden (Abb. 36). An den Wänden korrespondierte damit häufig eine schwarze Orthostatenzone, jedoch helle, oftmals gelbe Sockelzonen und polychrome Quaderreihen (gelb, violett, grün) über den Köpfen. Gerade diejenigen Decor-Zonen, die für den Betrachter besonders haptisch erfahrbar wurden - Böden und mittlere Wandzone -, waren damit dunkel gefasst. In den halbdunklen Atrien dürfte die Helligkeit dadurch noch einmal deutlich zurückgenommen worden sein. In den helleren Peristylen schluckte die Orthostatenzone Licht, umso heller müssen die Oberzonen im Sonnenlicht gestrahlt haben. In den Aufenthaltsräumen ist demgegenüber ein anderes Farbspektrum eingesetzt worden. In der Casa del Fauno zeichnen sich die größeren und helleren Triclinia durch polychrome Orthostaten und eine reiche Polychromie in der Oberzone aus. Statt dunkler Estrichböden kommen weiße Lithostrota oder weiße Mosaikpavimente zum Einsatz, um die ohnehin mit Tageslicht versorgten Räume zusätzlich hell zu machen. In den dunklen Cubicula am Atrium hat man darauf keinen Wert gelegt, sie besitzen dunkle Estrichböden. Ein solches Korrelat von Raumhelligkeit, Pavimenttyp und Wandgestaltung, wie es in der Casa del Fauno anzutreffen ist, findet in anderen Häusern wie der Casa di Sallustio (Abb. 117) eine gewisse Entsprechung. Zwar besitzt das Haus einfache Estrichböden, in Tablinum (19), Triclinium (22) sowie im Durchgang (22) kamen hier jedoch weiße und damit Helligkeit erzeugende Lithostrota zum Einsatz. Ein solches ,Farbmuster kam aber nicht in allen Häusern zum Tragen. An den Wänden zeigt sich, wenn man verschiedenste Häuser berücksichtigt, dass senkrechte Orthostaten und reiche Polychromie nicht nur in großen hellen Aufenthaltsräumen, sondern auch in kleinen, dunklen Cubicula zum Einsatz kommen konnten. Die Farbigkeit der Wand erweist sich als eine Form der Raumnobilitierung, die nicht auf die Beleuchtung eines Raumes reagiert. Dies gilt auch für aufwendige Frieszonen, die üblicherweise nicht auf einen bestimmten Lichteinfall hin kalkuliert sind. 
Für den zweiten Stil hat sich am Beispiel der Casa del Labirinto gezeigt, dass sich die auf der Nordseite des Peristyls gelegenen Räume hinsichtlich ihres Raumvolumens und ihrer Ausstattung erheblich unterschieden. Der korinthische Oecus und die angrenzenden Cubicula mit ihren weißen Mosaiken und zentralem Emblema dürften ausgesprochen hell ausgefallen sein, während das Opus signinum des langgestreckten, ohnehin dunklen Triclinium (39) und das Rautenpaviment in Oecus (40) die Räume dunkler gemacht haben. Die besonders herausgehobenen Räume zeichnen sich folglich durch einen besonders hellen Raumeindruck aus. Während am Boden eine gewisse Differenzierung der Helligkeitswerte zu greifen ist, fallen die Farbwerte der Wände in allen Räumen ähnlich aus. Unabhängig vom jeweiligen Raumzuschnitt und Wandaufbau handelt es sich um Gelb- und Rottöne, die eine warme Raumatmosphäre erzeugen. Insbesondere in den kleinen Cubicula dürfte dies zur Steigerung von Intimität beigetragen haben. Tatsächlich ergibt sich jedoch auf einer anderen Ebene ein Korrelat zwischen der Helligkeit des Raumes und der Wandmalerei: Es sind die hellen, auf den Garten geöffneten Räume, die mit komplexen Architekturprospekten ausgestattet sind. Diese waren folglich im Tageslicht gut sichtbar.

Im dritten Stil hat die Diversifizierung von Raumqualitäten und Ausstattungsoptionen ein breites Spektrum erreicht, sodass jeder Raum in ganz spezifischer Weise ,designed` wurde. Einen neuartigen Effekt hatten einerseits die Schwarz-Weiß-Mosaiken, andererseits die neuen Farbwerte der Wandmalereien. Die bichromen Mosaiken wurden verschiedentlich dazu eingesetzt, das zuvor mit dunklen Estrichböden ausgestattete Atrium und seine anschließenden Räume mit einem weißen Grundpaviment zu versehen. Dies gilt für Domus VIII 2,14-16 (Abb. 239), in der ein weißer Atriumsbereich mit dem schwarzen Tessellat der Sonnenterrasse kontrastierte. Dieses schluckte nicht nur Licht, sondern heizte sich in der Mittagssonne auch entsprechend auf und gab in den Abendstunden Wärme ab.

Zur atmosphärischen Qualität der Wohnräume trugen insbesondere die Wandfarben bei. Indem die Wand in der Mittelzone durch große Paneele gegliedert wird, entfalten Farbwechsel eine besondere Wirkung. Diese wird noch einmal gesteigert, wenn stark kontrastierende Farben zum Einsatz kommen - Schwarz-Rot-Kontraste etwa. Im Vergleich zu den vorausgehenden Phasen gänzlich neu ist jedoch die Gestaltungsidee, monochrome Räume zu schaffen und Polychromie dadurch ganz zurückzunehmen. Die Raumwirkung fällt dadurch naheliegender Weise ausgesprochen homogen aus. Dass in ein und demselben Haus sehr unterschiedliche ,Farbmuster zum Einsatz kommen konnten, hat sich besonders deutlich an der Casa di Marcus Lucretius Fronto gezeigt. Mit dem monochrom schwarzen Atriumsraum (Abb. 279-286) korrespondiert ein Tablinum, das sich durch auf Kontrastwirkung angelegte Farbwechsel von Gelb, Schwarz und Rot auszeichnete (Abb. 288). Ähnliche Unterschiede ergeben sich in der Gestaltung der an das Atrium angrenzenden Cubicula. Während Cubiculum (c) monochrom weiß ausfällt (Abb. 303-305), entspricht Cubiculum (g) in seiner Farbwahl dem Tablinum (Abb. 306-312). Bei aller Diversität ist aber auch erkennbar, dass neue Töne zur Farbpalette hinzukommen. Dies gilt für pastellige Farben, insbesondere für helle Blautöne ${ }^{37}$. Sie kommen in den Gartendarstellungen zum Einsatz, im Atrium der Casa dei Quadretti teatrali (I 6,11) wählte man ein helles Blau für die großformatigen Paneele der Mittelzone (Abb. 334-336). Zu den warmen Rot- und Gelb-Tönen des zweiten Stils kommen damit kühlere Farben hinzu.

Für alle Stilphasen zeigt sich, dass zwar die Farbwahl der Böden auf die Lichtverhältnisse Bezug nehmen konnte und insbesondere große Aufenthaltsräume durch einen hellen Boden noch einmal heller wirkten. An den Wänden hat man auf einen solchen Effekt jedoch verzichtet, die Farbwahl reagierte nicht auf die Helligkeit eines Raumes.

37 Zur italischen Produktion von Ägyptisch Blau ab dem mittleren 1.Jh.v.Chr., s. Ling 1991, 208; Cavassa - Delamare Repoux 2010, 237-241. 
Bisher sind Licht und Schatten als Qualitäten des real erlebbaren Raumes diskutiert worden. Decor- und Bildkonzepte operieren jedoch mit einer Vorstellung von Licht und Schatten. Und hier ergeben sich im Laufe der Zeit tatsächlich Unterschiede.

Im ersten Stil wurden Licht- und Schattenspiele an der Wand durch die plastische Differenzierung von Quaderspiegel und Randschlag ${ }^{38}$ sowie durch die plastische Gestaltung von Frieszonen und Epistyl erreicht, die minimale Schatten auf der dem Licht abgewandten Seite erzeugten. Der Schattenwurf entsprach damit den realen Lichtverhältnissen, welche die Wand modellierten. Allerdings ,funktioniert' die Licht-Schatten-Modellierung nur bei einem relativ gleichmäßig den Raum erhellenden Licht. Wenn bei tief stehender Sonne ein Lichtkegel auf eine Wand fiel, so leuchteten die Farben in diesem Wandabschnitt geradezu gleißend, die systematische Wirkung des Wandaufbaus wurde dadurch empfindlich gestört. Nur im Ausnahmefall wurden im ersten Stil Decor-Elemente malerisch und damit perspektivisch umgesetzt, etwa Mäander- oder Pfeifenfriese. In diesen Fällen stellten hellere und dunklere Farbwerte die Illusion von Licht und Schatten her. Nicht zuletzt sind auch die Opera vermiculata durch einen differenzierten Umgang mit Licht und Schatten gekennzeichnet. In den figürlichen Emblemata wurden die Akteure ins Licht gesetzt, durch Licht- und Schattenspiele die perspektivische Wirkung der Figuren geschärft. Regelrecht inszeniert sind Licht-Schatten-Effekte in der ,Felsformation', über die der Bacchus-Amor der Casa del Fauno auf seinem Tiger-Löwen hinwegreitet (Abb. 24).

Im zweiten Stil reagierten die gemalten Licht- und Schatteneffekte auf das vom Eingang her einfallende Licht ${ }^{39}$. „Neben bzw. über [der Eingangstür] streben zwei Lichtgänge auseinander und setzen sich in den Seitenwänden fort. Für das Zusammenführen dieser Stränge dient idealerweise die dem Ausgangspunkt der Lichtrichtungen gegenüberliegende Wand. “40 Die Wandbilder setzten folglich ein symmetrisch, durch das axiale Zentrum der Eingangswand einfallendes, sich gleichmäßig verteilendes, zugleich aber diffuses Licht voraus. Wahrnehmbar wird es in Gestalt von Glanzeffekten und Körperschatten, welche die Architekturelemente modellieren ${ }^{41}$. Allerdings bricht auf den Wänden zweiten Stils nicht nur die perspektivische Logik, indem man auf verschiedene mögliche Betrachterstandpunkte Rücksicht nimmt. Auch auf eine konsequent-kohärente Licht-Schatten-Modellierung der Wände hat man verzichtet ${ }^{42}$.

Im dritten Stil wurden Licht und Schatten eingesetzt, um die Scheinarchitekturen (insbesondere in der Oberzone), aber auch die Bildelemente selbst effektvoll in Szene zu setzen. In der Sockel- und Mittelzone besitzen die verschiedenen Bilder, Bildobjekte und Ornamente jeweils ihre eigene Lichtquelle, während in den Oberzonen eine zumeist axialsymmetrische Lichtführung in den Dienst einer ,Ornamentalisierung' der Wand tritt. In den Schwarz-Weiß-Mosaiken wurde auf die Angabe von Schatten meist ganz verzichtet (Abb. 244. 375. 383). Da die Darstellung bei den bichromen Mosaiken auf Kontrast angelegt ist, würde eine Schattenmodellierung die Bilder verunklären. Gerade bei den komplexeren Bildthemen des dritten Stils konnte einfallendes Sonnenlicht die Bildwahrnehmung empfindlich stören (Abb. 415). So wundert es nicht, dass Vitruv für Pinakotheken eine Ausrichtung nach Norden empfiehlt, weil hier keine störenden Lichtkegel auftreten - die Räume stattdessen gleichmäßig erhellt wurden ${ }^{43}$. Allerdings folgte man dieser Empfehlung nicht, war doch die Ausrichtung der Räume, wie gesehen, maßgeblich durch die Orientierung des gesamten Grundstücks bedingt.

38 Zu diesem Phänomen in der, realen` Architektur, s. Grüner 2014a, 432f. 435.

39 Ascherl 2002, 21-24 spricht bei einer solchen Anpassung der gemalten Lichteffekte an die reale Beleuchtungssituation von einem Standortlicht. Sie kommt für den zweiten Stil zu dem Ergebnis (S. 280), dass die Lichtführung zumeist auf die Tür eines Raums, nur im Ausnahmefall jedoch auf seine Fenster hin kalkuliert worden sei.

40 Einschlägig Ascherl 2002, bes. 21.

41 Ähnlich Grüner 2014a, 441f.

42 Tybout 1989, $35 \mathrm{f}$.

43 Vitr. 1,2,7. 


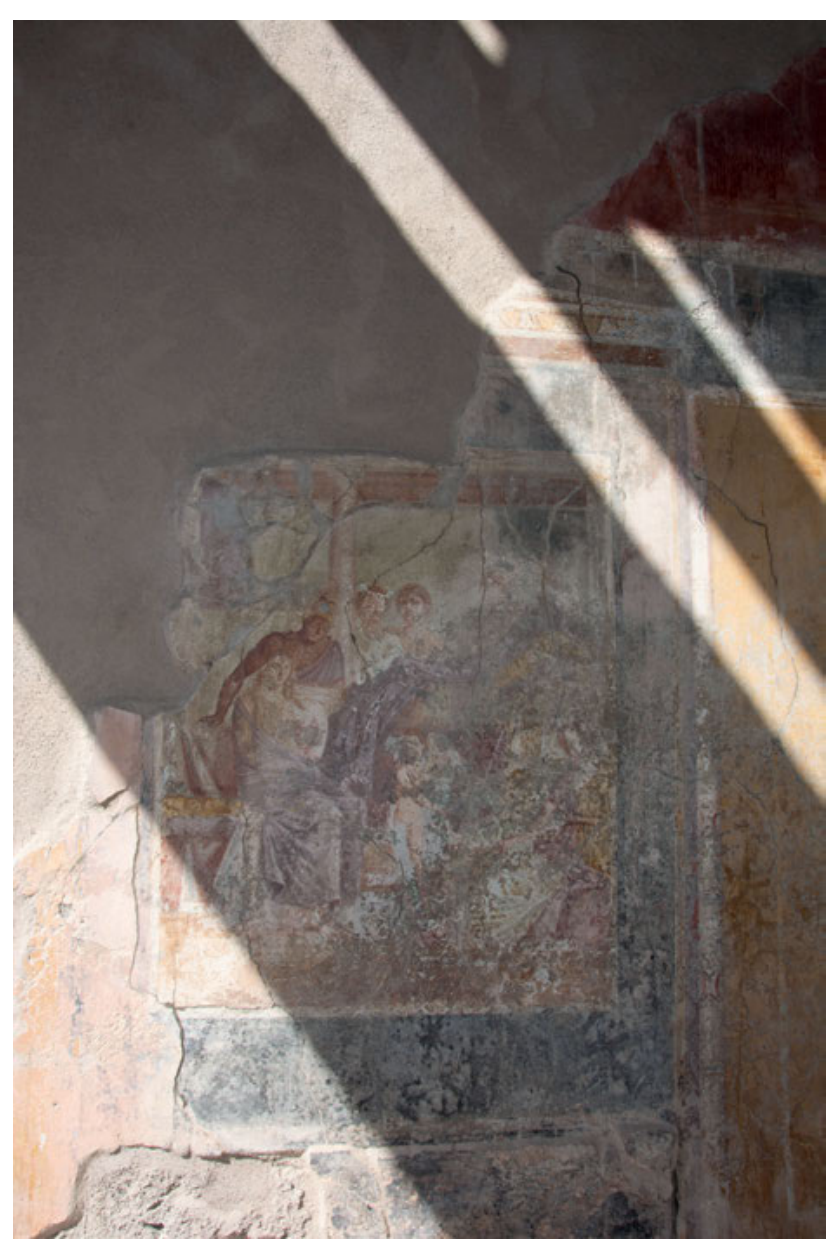

Abb. 415: Casa annessa alla Casa dell'Efebo $(17,19)$, Tablinum mit Lichteinfall.

\section{Klang und Geräusch}

Das Haus als Decor-Raum lässt sich auch mit Blick auf seine Soundscape befragen. Nur manche Klangereignisse sind jedoch gezielt ,gestaltet', üblicherweise ereignen sich Geräusche akzidentiell. Für beide Sound-Situationen gilt, dass ihre Wirkung von den Klangeigenschaften der Raumordnung abhängt.

Die mächtige Hausfassade stellte nicht nur eine optische Schranke, sondern auch eine akustische Barriere her. Zwar hat Hannah Platts zu Recht darauf verwiesen, dass Geräusche, die auf der Straße und in den anliegenden Geschäften ihren Ursprung hatten, an die physischen Schranken der Architektur nicht gebunden waren, sondern diese transgredierten, woraus sich eine Verschränkung von öffentlichen und privaten Klangkulissen ergab ${ }^{44}$. Auch antike Autoren klagen nicht selten über störende Geräusche, die aus den Nachbargebäuden in den Wohnraum dringen ${ }^{45}$. Allerdings ist für Rom eine deutlich höhere Wohndichte in Rechnung zu stellen. Für Pompeji indes zeigt sich selbst im heutigen, ruinösen Zustand der Häuser, denen üblicherweise Dächer, vor allem aber Türen fehlen, dass von dem umgebenden Lärm in den Atrien und insbesondere in den Peristylen kaum etwas ankommt. Erlebbar wird dies beispielsweise am Nordatrium der Casa del 
Citarista (I 4,5.6.25.28; Plan 5), an dem die Via dell'Abbondanza (mit ihren heute lärmenden Touristen) vorbeiführt.

Das hohe Atrium als Knotenpunkt des häuslichen Lebens dürfte einen gewissen Nachhall besessen haben. Durch die zahlreichen Aktivitäten, die hier zusammenliefen, wird es eine entsprechend komplexe Geräuschkulisse geboten haben. In den Peristylen hingegen verlor sich der Schall in den offenen Himmel, zwischen die menschlichen Stimmen dürfte sich Vogelgezwitscher gemischt haben. Insbesondere Geräusche, die an tägliche Arbeit erinnerten - das Klappern von Kochtöpfen etwa - wurde in größeren Häusern wie der Casa del Fauno (Plan 1) und der Casa del Labirinto (Plan 2) in separate Bereiche ausgelagert. Die Raumstruktur erzeugte folglich auch eine akustische Ordnung des Hauses.

Der Decor trug kaum zur Differenzierung akustischer Situationen bei. Die verputzten Wände aller Räume waren glatt und reflektierten Schall, ähnliches gilt für die Estrich- und Mosaikböden. Eine akustische Differenzierung wird sich allerdings durch das Vorhandensein bzw. Fehlen von Stoffen, Teppichen und Möbeln ergeben haben. Einen ganz besonderen Einfluss auf die Geräuschkulisse der Häuser hatte seit der frühen Kaiserzeit aber die Anlage von Wasserspielen und Nymphäen mit Fließwasser. Das plätschernde Geräusch des Wassers stattete die zentralen Höfe des Hauses mit einem homogenen Geräuschteppich aus.

\section{7. ,Bild' und ,Ornament': Bildkonzepte im Wandel}

Die Decor-Phänomene, die in der Zeit zwischen dem 2.Jh.v.Chr. und dem 1.Jh.n.Chr. greifbar werden, lassen sich als Auseinandersetzung mit verschiedenen Konzepten von Bildlichkeit und Ornamentalität begreifen. Die Antike hat sich von diesen Phänomenen jedoch einen anderen Begriff gemacht ${ }^{46}$.

Für Vitruv sind mit ordinatio, dispositio, eurythmia, symmetria, decor und distributio zentrale Ordnungs- und Gestaltungsprinzipien von Architektur benannt ${ }^{47}$. Ornamentum wird in dieser Logik als Form der Ausstattung verständlich, die den Prinzipien des decor gehorcht, damit aber auch die Bedeutung von Schmuck und ,Auszeichnung، im umfassendsten Sinn annehmen kann. Der Begriff ist in der Antike damit gerade nicht als Gegenbegriff zum Bild angelegt. Statuen können etwa als ornamentum eines Theaters fungieren ${ }^{48}$, signae und tabulae pictae zum ornamentum der Stadt werden ${ }^{49}$.

Zur Bezeichnung von Bildern stehen die Begriffe imago und pictura zur Verfügung, die bei Vitruv in ein spezifisches Verhältnis zueinander gesetzt werden. Während imago das im Bild Dargestellte bezeichnet, meint pictura bestimmte Fertigkeiten und Techniken, die ein Bild als Gegenstand hervorbringen ${ }^{50}$. Die beiden Begriffe lassen sich somit auf die Differenz von Bild und

46 Zu einer knappen Begriffsgeschichte des Ornaments in der Neuzeit, s. Beyer - Spieß 2012; Squire 2018, bes. 16-22. 47 Vitr. 1,2,1f.

48 Plin. nat. 7,34: Pompeius Magnus in ornamentis theatri mirabiles fama posuit effigies, ob id diligentius magnorum artificum ingeniis elaboratas. Übers.: „Pompeius der Große brachte unter den Verzierungen des Theaters auch Bilder im Gerede des Volkes berühmt gewordener Personen an, welche zu diesem Zweck von der Geisteskraft großer Künstler besonders sorgfältig gearbeitet waren.“

49 Cic. Verr. 2,1,58: Dices tua quoque signa et tabulas pictas ornamento urbi foroque populi Romani fuisse. Übers: „Du wirst versichern, auch deine Statuen und Gemälde hätten der Stadt und dem Forum des römischen Volkes als Zierde gedient.“

50 Vitr. 7,5,1: Namque pictura imago fit eius, quod est seu potest esse, uti homines aedifi/cia, naves, reliquarumque rerum, e quibus finitis certisque corporibus figurata similitudine sumuntur exempla. Übers. Grave 2015, 30: „Denn durch das Gemälde [pictura] wird ein Bild [imago] dessen geschaffen, was ist oder sein kann, z. B. Menschen, Gebäude, Schiffe und andere Dinge. Von diesen ganz festumrissenen und bestimmten Dingen werden ähnlich gebildete Nachbildungen entlehnt.“ 
Bildträger beziehen ${ }^{51}$. Imagines fallen schon im antiken Verständnis nicht mit der Wirklichkeit zusammen, sondern definieren sich - wie Gottfried Boehm es in unserer Zeit formuliert - über ihre ikonische Differenz ${ }^{52}$. Sie manifestieren sich materiell (als pictura), sie übersteigen jedoch das Faktische und produzieren ein Mehr an Sinn (als imago) ${ }^{53}$.

Vor dem Hintergrund dieser antiken Termini ist nicht zu erwarten, dass sich in der häuslichen Ausstattung ein systematischer Unterschied zwischen Bild im emphatischen Sinn und ,Ornament in seiner neuzeitlichen Bedeutung als Schmuckelement greifen lässt. Und tatsächlich hat die vorausgegangene Analyse eine Vielzahl an Aspekten erbracht, die für die relationale Hervorbringung von ,Bildlichkeit‘ entscheidend sind ${ }^{54}$ :

- die semantische Komplexität der Darstellung (z.B. Mythenbild versus Einzelfigur);

- die Bildsyntax (Komplexität versus Durchmusterung);

- die Gestaltung der Bildgrenzen (Rahmung versus Nicht-Rahmung);

- der Ort der Präsentation (zentral versus marginal);

- die Darstellungsgröße;

- die Farbigkeit (Bichromie versus Polychromie);

- das Bildvolumen (rundplastisch, reliefiert, zweidimensional);

- die Präsentationsform (repetitiv-durchmustert/isoliert-singulär);

- die Exzeptionalität bzw. Typengebundenheit des Bildentwurfs.

In ein und demselben Kontext, selbst auf einer Wand, können diese Darstellungsmodi vielfältige, auch widersprüchliche Verbindungen eingehen. Decor-Systeme geben zwar eine ,Anleitung ' an die Hand, welcher ikonische ,Stellenwert' (d.h. welche ,Bildhaftigkeit') einem Decor-Element zukommt. Es ist aber immer auch der Betrachter, dessen Aufmerksamkeit sich auf einzelne DecorElemente richtet und der ihnen dadurch einen bildhaften Status verleiht. Schon die Antike kennt somit verschiedene Grade und Intensitäten von Bildlichkeit, die von einem ikonographisch dichten Bild bis zu einer einfachen figürlichen oder auch nicht figürlichen Darstellung (,Ornament') reichen. Vor dem Hintergrund solch allgemeiner Überlegungen lässt sich die Decor-Geschichte zwischen dem 2.Jh.v.Chr. und dem späteren 1.Jh.n. Chr. als ein Experimentieren mit unterschiedlichen Modi der Bildlichkeit auffassen - bzw. als eine immer wieder neue Gestaltung der BildOrnament-Relation.

\section{,Bild‘ und ,Ornament' im ersten Stil}

Im späten 2. und beginnenden 1.Jh.v.Chr. stellt der erste Stil ein ,Bild‘ einer Quaderwand vor. Dieses Bild ist mit seinen bunten Quadern und seinen Stuckgesimsen ornamental verfasst - vorgestellt wird eine ornamental gestaltete Wand, die durch ihre Formen, Farben und ihre imaginierte Materialität wirkt. Durch seinen Bezug auf die Architektur, seine Plastizität und auch die fehlende Rahmung gibt das ,Wand-Bild‘ vor, die reale Wand ,zu sein‘. Es verleugnet seine Bildlichkeit. Allerdings wird die Illusion an verschiedensten Stellen des Wandaufbaus gebrochen. Das WandBild gibt sich als Bild zu erkennen. Mit dem weitgehenden Verzicht auf figürliche Darstellungen

51 Grave 2015, 29-35 verfolgt das Begriffspaar von der Antike bis in die Renaissance. Bei Edmund Husserl ist die Differenzierung von physischem Bild, Bildobjekt und Bildsujet explizit benannt - vgl. Husserl [1904/05] 2006, 21; s. zur Frage von pictura/imago mit etwas anderer Auslegung bei Mitchell [1984] 2008; mit der Differenzierung von seeing in und seeing as, Wollheim 2003, der sich auf die Gestaltpsychologie bezieht; eine ausführliche kritische Diskussion von Wollheims Modell bei Grethlein 2017, bes. 154-168.

52 Boehm 1978, 118-138.

53 Gadamer 2010, 143.

54 Einzelne Aspekte, insbesondere die Wahrnehmungshaltung der Betrachter, sind auch bei Hölscher 2018, bes. 299333 diskutiert. 
fällt die formal und farblich rhythmisierte Quaderstruktur ins Auge, die sich als ,Ornament der Wand auffassen lässt.

Figürliche Darstellungen im engeren Sinn bleiben in dieser Zeit die Ausnahme. In der für ihre Zeit charakteristischen Casa di Sallustio (VI 2,4) fehlen figürliche Darstellungen am Boden gänzlich. Bildelemente bleiben vielmehr auf wenige, liminale Zonen beschränkt und fallen semantisch ,schwach“ aus. Die Marginalisierung betrifft insbesondere die ,Bilder', die den Baukörper, schmücken': die figürlichen Kapitelle der Eingangspilaster ${ }^{55}$, von denen eines einen bärtigen Silen und einen Flöte spielenden Satyr zeigt, sowie die Löwenkopfwasserspeier am Compluvium ${ }^{56}$ (Abb. 89). Silen und Satyr machen am Portal eine dionysisch-festliche Stimmung auf, ohne dass eine narrative Konkretisierung vorgenommen würde. Wie schon gesehen eignen sich dionysische Themen für vielfältige Bedeutungszuschreibungen. Noch breiter ist das Assoziationsspektrum der Löwenkopfwasserspeier, bei denen es sich zudem um ein stark standardisiertes Motiv für Dachterrakotten handelt. Mit Pilastern und Dachterrakotten sind es Zonen des Übergangs, die mit Bildelementen besetzt werden. Dieser Logik folgen auch die wenigen gegenständlichen Wandmalereien im Haus, deren Status zwischen Bildfriesen und gemalten Architekturfriesen changiert. Es handelt sich um die vegetabilen Friese im Tablinum (19) (Abb. 113) und Oecus (22). Sie verweisen zwar auf Naturhaftes, entbehren jedoch jeder narrativen Dichte. Vor allem aber fallen sie entsprechend klein aus und kommen nur dann ,in den Blick', wenn sich der Betrachter darauf ,einstellt' und nach oben blickt. In anderen Häusern der Zeit sind auch ikonographisch dichtere Sujets bekannt - Vogeldarstellungen, Reiterfriese, oder wie in der Casa del Fauno ein Kentaurengelage. Vielfach bleiben die Darstellungen jedoch auf ,liminale“ Frieszonen beschränkt. Auch die Monochromie zahlreicher Darstellungen trägt zu einer ,Einschränkung'von bildlicher Wirkung bei.

Mit diesem weitgehenden Fehlen von gegenständlichen Darstellungen und einer ,Marginalisierung' der tatsächlich vorhandenen Bildelemente ist die Casa di Sallustio charakteristisch für ihre Zeit. Insbesondere mit Blick auf die Wandgestaltung darf man von einem ,ornamentalen Modus، der Raumausstattung sprechen ${ }^{57}$. Das Hauptinteresse der Betrachter dürfte dem ästhetischen Erscheinungsbild von Räumen gegolten haben, d.h. ihrer Form und ihrer Materialität ${ }^{58}$. Eine solche Rezeptionshaltung spiegelt sich in den mobilen Objekten des Haushalts: Keramik und bronzene Gefäße verzichten geradezu vollständig auf Darstellungen. In dieser Vorliebe für das Ornamentale unterscheiden sich die Häuser nicht grundsätzlich von öffentlichen Kontexten. An öffentlichen Plätzen bleiben Bilder weitgehend auf Ehrenstatuen beschränkt, allein Heiligtümer dürften mit ihren Kult- und Votivstatuen, aber auch mit der hier ausgestellten ,Beutekunst‘, schon frühzeitig ein Ort verdichteter Bilderfahrung gewesen $\operatorname{sein}^{59}$.

Am Ende des 2.Jhs.v.Chr., vor allem dann aber im beginnenden 1.Jh.v.Chr., findet in die Häuser mit den Mosaikemblemata ein neues Konzept von Bildlichkeit Eingang. Mit der Casa del Fauno ist ein Prunkhaus diskutiert worden, das mit besonders zahlreichen Boden-Bildern ausgestattet wurde (Abb. 19. 21. 23. 24. 27. 42). Es handelt sich um verhältnismäßig große Bildfelder, die üblicherweise in der zentralen Raumachse platziert sind. Im Vergleich zu bisherigen Bildfindungen fallen die Darstellungen deutlich komplexer aus. Ein Rahmen fasst sie ein und hebt sie zugleich vom Boden ab, der zum Hintergrund wird. Erstmals wird ikonische Differenz explizit markiert. Mit dem Auftreten komplexerer figürlicher Bilder gewann Decor über seine allgemeine Funktion als Anzeiger von Prestige und Luxus hinaus eine diskursive Funktion, wurde zum Medium der Kommunikation und Interaktion. Die frühen Emblemata bleiben inhaltlich aber auffällig offen. Dies gilt für das weite Feld der Tierdarstellungen ebenso wie für ,dionysische‘ Themen. Zumeist handelt es sich um Bilder, die auf gängige Typen rekurrieren. Für diese, generischen“

55 Laidlaw - Collins-Clinton 2014, 54 Abb. 2. 2a.

56 Laidlaw - Collins-Clinton 2014, 57 Abb. 26a-d.

57 Zur Terminologie: Bauer 1962, 21.

58 Lorenz 2015, 257; Grüner 2017.

59 Zu Schriftquellen Neudecker 2015, 130-133. 
Bilder darf man annehmen, dass sich ihre Sinnpotenziale in Bezug auf spezifische Formen der Interaktion erschlossen. Zumindest mit dem Alexandermosaik hat das Haus aber ein ausgesprochen exzeptionelles, dichtes ,Bild“ besessen. Wenig später - greifbar etwa in der Casa del Labirinto - kommen mythologische Bildinhalte hinzu, mit denen ein neuartiges kommunikatives Potenzial gewonnen ist. Mosaikemblemata bleiben jedoch in einer gewissen Hinsicht immer auch ,marginal': Ihre Präsentation am Boden, wo sie nur in Schrägsicht oder gar auf dem Kopf betrachtet wurden, nimmt ihre Bildqualitäten zurück. Die Bildlichkeit löst sich beim Betreten des Mosaiks regelrecht unter den Füßen des Betrachters auf.

Vielleicht nicht zufällig ist es auch die prunkvoll ausgestattete Casa del Fauno, in der mit dem tanzenden ,Faun' ein besonders frühes, dreidimensionales Bildobjekt Aufstellung fand. Durch seine Sockelung erhält es eine ,Rahmung', die es aus der Umgebung heraushebt. Seine Platzierung in der zentralen Achse des Hauses rückt es in den Fokus der Wahrnehmung. Eine gewisse Zurücknahme von Bildlichkeit, gewissermaßen eine ,Ornamentalisierung', stellt sich jedoch durch das kleine Format ein. Die Statue tritt dem Betrachter nicht auf Augenhöhe entgegen, sondern wird als ornamentum des umgebenden Raums wahrnehmbar.

Bilder und Bildelemente sind in dieser Zeit nicht nur eine Seltenheit, sondern auf ,luxuriöse‘ Kontexte beschränkt: innerhalb von Häusern auf prunkvolle Aufenthaltsräume, innerhalb der Stadt zumeist auf besonders große Häuser. Mit ihrer dichten (Bild-)Ausstattung steht die Casa del Fauno jedoch am Beginn einer Trendentwicklung: Im Verlauf des 1.Jhs.v.Chr. nimmt die Komplexität und Dichte von Bildphänomenen in Häusern immer weiter zu.

\section{,Bild‘ und ,Ornament` im zweiten Stil}

Mit dem zweiten Stil sind für die Wände neue Decor-Formen gefunden, die Bildlichkeit in ganz neuartiger Weise ausloten. Indem der Wandaufbau nicht in Stuck, sondern in Malerei umgesetzt wird, verstärkt sich der bildhafte Eindruck. Die perspektivischen Architektur-Illusionen öffnen nicht nur die Wand, sie werden im engeren Sinn zu einem Architekturbild, das Ausblicke gewährt, aber auch zur Bühne für die Präsentation verschiedenster Objektwelten. Je erfolgreicher die Suggestion eines Architekturraumes jedoch gelingt, desto stärker tritt die Bildlichkeit der Darstellung in den Hintergrund ${ }^{60}$. Das Bild schafft sich selbst ab. Die Gemachtheit und Bildlichkeit der Architekturprospekte wird allerdings an verschiedenen Stellen regelrecht zur Schau gestellt. So ergeben sich auf der nördlichen Rückwand des korinthischen Oecus der Casa del Labirinto zwischen zentralen und seitlichen Interkolumnien ganz unterschiedliche Durchblicke, die logisch nicht zusammengehören können (Abb. 157). Auch die Wandsysteme zwischen Klinenbereich und Vorraum stoßen üblicherweise aneinander, ohne architekturlogisch aufeinander Bezug zu nehmen (Abb. 189. 197. 198). Es sind damit gerade logische Brüche, welche die Darstellungen in ihrer Bildlichkeit erfahrbar machen.

Mit der ,Bespielung' der Scheinarchitektur durch Altäre, Wasserbecken, Fruchtkörbe und Masken, aber auch durch Tiere und menschliche Figuren gewinnt das illusionistische Bild an haptischer Konkretheit. Die Objekte und Figuren sind wie auf einer Bühne im Raum präsent. Sie werden nicht als Bild im Bild gedacht, sondern als Ausstattung bzw. Bevölkerung der Architektur. Erstmals treten damit aber im Zentrum der Wand, auf Augenhöhe des Betrachters, gegenständliche Dingwelten in Erscheinung. Sie erfüllen eine Doppelfunktion, sind sie doch Decor der (gemalten) Architektur, in Bezug auf die sie präsentiert werden, und Decor des Raumes, in dem sie sichtbar sind. Durch diesen doppelt codierten Decor werden die Prunkräume in besonderer Weise nobili-

60 Zum prekären Verhältnis von Spiegelbild und ,Ikonoklasmus‘, s. Boehm 1969, 28; erneut mit Blick auf Architekturdarstellungen der Renaissance Grave 2018, 29. 
tiert. Im Falle von Megalographien avanciert die ,Bevölkerung der Architektur zum eigentlichen ,Bildthema', der Mensch wird mit einem imaginären Gegenüber konfrontiert.

Deutlich häufiger als zuvor werden die Scheinarchitekturen zum Träger von figürlicher ,Architekturornamentik'. Diese kann die Gestalt von figürlichen Kapitellen oder Architekturfriesen annehmen. Erstmals emanzipieren sich solche ,Bilder‘ aber auch stärker von der Architektur. Dies gilt für Pinakes, die wie im Fall von Cubiculum (46) der Casa del Labirinto friesartig präsentiert werden (Abb. 171. 176). Es sind gerahmte Bilder, die als Bildtafeln vorgestellt werden ${ }^{61}$. Und doch wird ihr Bildcharakter durch ihre Monochromie einerseits, durch ihre Präsentation in einer Frieszone und ihre dadurch bedingte repetitive Reihung andererseits wieder zurückgenommen. Eine weitere Bilderfindung stellen Klapptürbilder dar, wie sie im Oecus (22) der Casa del Criptoportico (I 6,2; Abb. 207) auftreten. Wieder bleibt der Bildstatus aber ambivalent. Eine Fensterrahmung wird zur Bildrahmung, die Darstellung somit als Bild und Ausblick gleichermaßen verständlich. Die Einbindung der Klapptürbilder in einer Frieszone - mithin in eine ,Fensterzone - verstärkt ihren Bezug auf die Architektur. Ikonische Differenz wird nicht explizit gemacht, sondern verschleiert.

Mit dem Übergang zum dritten Stil wird ein weiterer konzeptioneller Schritt getan. Das Zentrum der Wand kann nun von einer Ädikula besetzt werden, die ein Landschaftsbild fasst. Erstmals tritt dem Betrachter im Zentrum der Wand, auf Augenhöhe, ein gerahmtes Bild entgegen. Das architektonisch gerahmte Bild changiert allerdings noch immer zwischen Ausblick und Tafelbild (Abb. 216). Mit dieser neuartigen Präsentationsweise ging ein thematischer Wandel einher. Als Mittelbilder besonders beliebt sind großformatige Landschaftsbilder, die von mythologischen Akteuren bevölkert werden konnten. Sie leisten eine narrative Verdichtung und Spezifikation der Bildinhalte. Mit der thematischen Konkretisierung geht allerdings eine assoziative Öffnung einher: Mythenbilder lassen sich zwar auf ihre narrative Vorlage hin befragen, sie bieten sich aber als Ausgangspunkt für mehr oder minder freie Assoziationen an. In sehr viel größerem Umfang als die ,alten` Bilder vermögen Mythenbilder als ,Konversationsstücke‘ zu fungieren.

Aus dieser neuen, verdichteten Bildlichkeit ergaben sich vielfältige intermediale Bezüge. Diese entwickeln sich einerseits innerhalb des Wandbildes, auf dem real gedachte Architektur und bildhaft gedachte Elemente, real gedachte Figuren und bildhaft gedachte Skulpturen, real gedachte Ausblicke und bildhaft gemeinte Landschaften miteinander in Beziehung treten. Sie ergeben sich aber auch zwischen gemaltem Bild und realem Ausblick aus dem Raum, zwischen gemalten Objekten und realen Objekten im Raum, zwischen gemalten Figuren und den realen Akteuren.

Diese komplexen Wandbilder, die verschiedene Modi von Bildlichkeit in Konkurrenz zueinander entfalten, bleiben im zweiten Stil den aufwendig ausgestatteten Aufenthaltsräumen vorbehalten. Bilder werden noch immer als ,exklusives' Gut aufgefasst. Es handelt sich dabei um Aufenthaltsräume unterschiedlicher Größe, darunter auch Cubicula.

Mit der Verdichtung von Bildphänomenen an der Wand ging eine Rücknahme von Bildlichkeit am Boden einher. An die Stelle gerahmter, polychromer Bildemblemata traten im späteren zweiten Stil ungegenständliche Ornamente und Muster, die das Raumzentrum und die Schwellen von Räumen besetzten. Wenn im Einzelfall doch figürliche Elemente zur Darstellung kamen, so waren diese auf einen bichromen Darstellungsmodus festgelegt. Gerade in den Schwellbereichen und im Zentrum eines Raumes war Figürliches auf isolierte Einzelmotive von geringer Größe beschränkt.

\section{,Bild` und ,Ornament‘ im dritten Stil}

Nach der Mitte des 1.Jhs. verlor die Architektur durch ihre massive Verschlankung an Dinglichkeit. Dies führte zu einer gänzlichen Umwertung des Wand-Decors, aus dem Architekturbild wurde ein

61 Hier soll auf Spekulationen, ob man in italischen Häusern mit Tafelgemälden auf Holz rechnen darf, verzichtet werden; mit guten Gründen kritisch Jones 2019, 18 f.; zur Diskussion realer Bildpaneele, s. Jones 2019, 71-88. 
ornamentales Gliederungssystem, das unterschiedliche ,Bilder‘ und ,Ornamente' rahmte. Bildlichkeit und Ornamentalität wurden in Bezug auf dieses abstrahierte System präsentiert, das verschiedene ,Stellen“ mit spezifischen Wertigkeiten belegt. Die zuvor ausführlich beschriebenen Phänomene sollen an dieser Stelle noch einmal kurz resümiert werden.

Im Zentrum der Wand treten dem Betrachter zumeist gerahmte und proportional besonders große Mittelbilder entgegen, bei denen es sich häufig um ikonographisch besonders ,dichte Mythenbilder handelt. Mit ihnen verbindet sich einerseits das Interesse am bildlichen Erzählen und an den sich aus der Narration ergebenden (kulturellen, religiösen, moralischen etc.) Assoziationen, andererseits das Interesse an der Charakterisierung der Beziehungen, die sich zwischen den Protagonisten entfalten. Da Mythenbilder in einem Raum üblicherweise als Sets auftreten, werden die Bild-Ensembles gezielt zur Stimulation von Metadiskursen eingesetzt.

Die Wandmitte kann alternativ dazu von ungerahmten Vignetten mit der Darstellung von Landschaften oder ,Stillleben“ besetzt werden. Neu im Spektrum vertreten sind Pinakes mit ägyptisierenden Darstellungen. Vor allem aber sind gerahmte wie nicht gerahmte Bildelemente nicht auf das zentrale Paneel beschränkt; sie finden sich ebenso auf den Seitenpaneelen, in der Sockel-, Predella- und Oberzone. Durch diese Bildervielfalt werden schon innerhalb einer Wand, dann aber auch innerhalb eines Raumes komplexe Assoziationsgeflechte möglich, aus denen eine ganz neuartige Form der Bilderfahrung resultiert.

Üblicherweise nimmt an der Wand die Dichte der Bildlichkeit ,zu den Rändern hin`ab. Auf den Seitenfeldern der Mittelzone sind es oftmals ungerahmte Vignetten, die sich von den (semantisch unbestimmten) ,Feldern' abheben, diese als Malgrund in Anspruch nehmen, dadurch aber auch den semantischen Status von Figur und Grund ambiguisieren. In der Sockel- und Predellazone finden sich vielfach Einzelmotive von massiv reduzierter Gegenständlichkeit, während in den Oberzonen das Architekturgestänge zum Träger von ornamenthaft präsentierten Bildobjekten werden kann. Durch Rahmung und Nicht-Rahmung, durch Darstellungsgrößen und Farben, durch die parataktische oder axialsymmetrische Präsentation von Bildfeldern und durch verschiedene Formen der Bilderzählung können ganz unterschiedliche Bild- und Ornamenteffekte erzeugt werden. Indem die Bilder eines Raumes üblicherweise (spiegel-)symmetrisch aufeinander Bezug nehmen, wird eine ornamentale Wahrnehmung aller Ausstattungselemente befördert. Freilich kann sich die Aufmerksamkeit auch auf Einzelelemente richten. All dies zeugt davon, dass sich mit dem Übergang zum dritten Stil eine ganz neue ,Lust am Bild‘ greifen lässt.

Diese manifestiert sich nicht allein an der Wand. In denselben Zeitraum fällt ein regelrechter Boom an dreidimensionalen Bildobjekten, die in die Häuser Eingang finden. Auch hier ergibt sich eine Spannung zwischen ,Bild' und ,Ornament‘. Insbesondere Atrien und Peristyle werden zum Schauraum für die Aufstellung von Skulpturen und anderen decorierten Objekten. Skulpturen beanspruchen durch ihre Dreidimensionalität denselben ,Realraum‘ wie der Betrachter und werden dadurch haptisch erlebbar. Doch auch bei den Skulpturen wird der Bildcharakter auf verschiedene Weise ambiguisiert.

Einen erheblichen Einfluss auf die ,Bildhaftigkeit‘ hatte auch bei den Skulpturen ihre Präsentationsform. Brunnenfiguren und Marmorskulpturen stehen häufig in der Achse des Atriums, in den Peristyl-Nymphäen können Skulpturen eine zentrale Nische besetzen. In beiden Fällen werden sie ins Zentrum der Aufmerksamkeit gerückt, eigene Sockel unterstreichen das ,Herausheben“ aus dem Raum. Durch die Architektur besonders inszeniert sind auch die Porträthermen, die vor den Anten des Tablinums aufgestellt sind. Ihr visueller Status changiert in Abhängigkeit davon, ob sie als von den Anten hinterfangene Bilder oder als Ornamentum der Architektur aufgefasst werden. Wenn Skulpturen am Peristyl in einer ganzen Reihe von Nischen aufgestellt sind, so nimmt sich ihre Präsentation stärker sequenziert und rhythmisiert, und darin ornamentalisiert aus. Dies gilt in besonderer Weise für die in den Interkolumnien aufgehängten Oscilla. Je nach Anbringungshöhe werden sie wohl vor allem, en passant‘ wahrgenommen worden sein.

Eine wichtige Rolle spielt die Größenreduktion. Durch das kleine Format ist die ,Präsenz‘ der Skulpturen zurückgenommen, sie treten nicht unmittelbar mit dem Betrachterkörper in Konkur- 
renz. Zugleich wird dadurch ihr Bildcharakter erfahrbar, die Objekte werden zum Ornamentum des Raumes.

Entscheidend für die ,Bild'-Wirkung ist auch das Sujet. Bei aller physischen Präsenz der Skulpturen verzichtete man auf narrativ verdichtete Aussagen. Figuren bzw. Figurengruppen wirkten zunächst einmal ,für sich'. Dies bedeutet, dass mit den dionysischen und aphrodisischen Figuren insbesondere Protagonisten des Lebensgenusses in die zentralen Höfe des Hauses Eingang fanden - Akteure, die sich durch ihre Posen den Blicken der ,Zuschauer gezielt aussetzten. Eine nochmals gesteigerte Aufmerksamkeit dürfte den Porträthermen und Porträtbüsten entgegengebracht worden sein. Das Repräsentationsbedürfnis der Hausbesitzer gewann in diesen Medien eine neue, spezifische Ausdrucksform: Repräsentation war jetzt über die Individualisierung eines Bildes möglich. Das Anlitz eines Menschen trat dem Betrachter geradezu leibhaftig entgegen. In diesen Fällen wird jedoch eine andersartige Form der Bild-,Reduktion‘ vorgenommen. Die reale körperliche Präsenz ist durch die Darstellungsform zurückgenommen - handelt es sich doch um Abbreviaturen des menschlichen Körpers.

$\mathrm{Zu}$ einer Ambiguisierung des Bildcharakters trug die multisensorische Einbettung von Bildern bei. So binden die Brunnenskulpturen in ein komplexes, multisensorisch wahrnehmbares BildEnsemble ein, das im Fall der Nymphäen durch vielfache intermediale Verknüpfungen verdichtet wird. In Bezug auf ein maximal aufgeladenes atmosphärisches Setting stellt sich eine beiläufige ,Bild'-Wahrnehmung ein. Noch einmal gesteigert ist eine solche Beiläufigkeit dann, wenn mobile Objekte in Handlungen eingebunden waren. Reliefierte Conviviums-Gefäße, die man in die Hand nehmen musste, boten eine haptische Bilderfahrung, die jedoch durch den Geruch und Geschmack von Essen und Getränken ,gerahmt‘ wurde.

Einen Sonderfall stellt die regelrechte Animation der Bilder dar ${ }^{62}$, die das Bild zum ,belebten Gegenüber macht. Zwar sind schon seit dem 2.Jh.v.Chr. figürliche Wasserspeier bekannt, die sich als solch animierte Bilder verstehen lassen. Nun gewinnt das Phänomen jedoch eine neue Vielfältigkeit. Herabhängende Oscilla bewegten sich im Wind, zogen dadurch Aufmerksamkeit auf sich und wurden regelrecht verlebendigt. Besonders konkret wird eine solche ,Animierung im Fall der Brunnenskulpturen, die den Wasserstrahl ,ausspeien'. Auf diese Weise erhalten Tierfiguren eine Stimme, aus einem Weinschlauch vermag Wein zu spritzen, männliche Figuren urinieren bisweilen in den Hof. Diese Verlebendigung und ,Konkretisierung ' der Skulpturen zielt jedoch zugleich auf eine Negierung des ,Bild'-Status.

Signifikant ist in augusteischer Zeit der Umstand, dass zahlreiche, zuvor unbebilderte, semimobile und mobile ,Gebrauchs'-Objekte zum Träger von gegenständlichen Ornament-Bildern wurden. Dies gilt für die Keramik, die bis dahin weitgehend unfigürlich war und für ihre ästhetischen, schwarzen Oberflächen geschätzt wurde. Die neuen roten Glanztonwaren, insbesondere die arretinische Ware, fungierten erstmals seit langer Zeit wieder als Bildträger. Ähnliches gilt für Terrakottalampen $^{63}$, für Bronze- und Silbergefäße. Gerade diese Bebilderung von Funktionsobjekten trägt entscheidend zu einer Steigerung der Bildpräsenz im Haus bei. Allerdings wurde in diesen Fällen Bildlichkeit durch eine Spannung mit dem Medium und dessen Gebrauchsfunktion zurückgenommen. So ordnen sich die figürlichen Tischstützen dem Tisch ganz konkret unter ${ }^{64}$.

All diese Phänomene zusammengenommen zeugen jedoch von einer massiven Zunahme des Interesses an ,Bildern'. Die neue ,Lust am Bild“ findet ihren Ausdruck somit in einem rein quantitativen Anstieg an figürlichen Darstellungen, in einer Vervielfachung von Bildmedien, Präsentationsformen und Darstellungsinhalten. Architektur und das decorative System wurden eingesetzt, um die ,Bilder` zueinander in Beziehung zu setzen. Dadurch wurde es möglich, ausgesprochen komplexe, ineinander verschränkte Bild-Ornament-Relationen zu erzeugen. Mit der Simulation ver-

$62 \mathrm{Zu}$ Bildern als ,Agenten“ liegt eine immense Literatur vor; mit einem Fokus auf ,animierte‘ Bilder insbesondere Bredekamp 2010, 34 f., der in diesem Fall von einem ,schematischen Bildakt“ spricht.

63 Wallace-Hadrill 2010, 387; Flecker - Haug 2017, 273-278.

64 Ausführlich dazu demnächst Adrian Hielscher. 
schiedener Bildformen auf einem Wandbild, mit der neuen Vielfalt an bebilderten Objekten bzw. Bildobjekten und visuell anspruchsvoll gestalteten Gärten ergaben sich vielfältige intermediale Verflechtungen ${ }^{65}$ - und mit diesen auch die Option einer Intellektualisierung von Bildlichkeit. An die Stelle eines Ornamentmodus ist nun bei der Ausstattung der Häuser ein Bildmodus getreten, der neue Formen der Perzeption, Interaktion und Kommunikation voraussetzte und zugleich stimulierte.

\section{Metaleptische Strategien}

Das Interesse am Bild ging mit Strategien der Stabilisierung und Destabilisierung des Bildes einher. Bilder besitzen das Potential, ihre eigene Bildlichkeit zum Gegenstand der Darstellung zu machen, ihre ontologischen und medialen Grenzen zu sprengen und dadurch zu reflektieren. Solche Grenzüberschreitungen umspielen und exponieren Bildlichkeit - und dies auf verschiedenen Ebenen. In ästhetischer Hinsicht fordern metaleptische Strategien die Aufmerksamkeit des Betrachters ein. Durch den Bruch mit gängigen Bildlogiken richtet sich dessen Interesse auf die Bildlichkeit des Bildes selbst. In medialer Hinsicht erlauben Transgressionen des Bildes, den Erzählraum der Darstellung auszudehnen - das Verhältnis von Realraum, Bildraum und dem Raum des Bildes im Bild zu thematisieren ${ }^{66}$. In semantischer Hinsicht wird es so möglich, den ontologischen Status des Bildes selbst zu thematisieren. In metaphorischem Sinn besitzen folglich auch metaleptische Bilder ein spezifisches ,narratives‘ Potential. Solche ,Bildbrüche‘ kommen in allen drei Stilen in verschiedenster Form vor, hier sollen einzelne, signifikante Aspekte noch einmal herausgegriffen werden.

Der erste Stil konzipiert die Wand als eine solide geschlossene Wand. Wenn einzelne Quader indes als Bildträger in Anspruch genommen werden, wird diese Illusion durch eine konträre (Meta-)Illusion gebrochen (Abb. 45. 105. 115). Besonders weit geht diese Ambivalenz dann, wenn die Bildfiguren mit der Marmor-Äderung des Quaders spielen. In den Scheinarchitekturen, insbesondere etwa den Scheintüren, treten Illusion und Illusionsbruch immer schon in eine Spannung zueinander (Abb. 107).

Im zweiten Stil werden neue Strategien entwickelt, um einen Illusionsraum herzustellen, die Wand öffnet sich und ist auf bestimmte Betrachterperspektiven hin angelegt. Die Bildhaftigkeit und mit ihr die Immersion in den Illusionsraum werden jedoch durch logische Brüche gezielt in Frage gestellt: Auf ein und derselben Wand können sehr unterschiedliche ,Ausblicke' ohne Vermittlung ,aneinanderstoßen' (Abb. 153. 157). Bildbrüche ergeben sich aber auch dann, wenn Bildelemente, die als Metabilder konkret auf die Architektur bezogen sind, aus dieser Logik ausbrechen: Greifen, die ihren Fries sprengen, Karyatiden, die sich zu bewegen beginnen, Statuen, die wie menschliche Körper agieren, Rankensäulen, deren vegetabiler Schmuck sich verselbständigt, nicht zuletzt aber auch Bilder, die zwischen Bildhaftigkeit und Ausblick changieren (Abb. 166-168. 207. 212. 220). Gerade die repräsentierten Bildobjekte transgredieren und ambiguisieren folglich ihren Status.

Der dritte Stil führt dieses Spiel mit Medialitäten und Realitäten fort. Das architektonische System als Ganzes wird ambiguisiert, architektonische Stützen gewinnen filigran-ornamenthafte Gestalt, können zu Pflanzenstängeln oder Kandelabern werden. Auf der Wand ,sichern` zwar Rahmungen den Status einzelner Bilder, insbesondere die Mittelbilder werden vielfach als Tafelbilder konzipiert. Die vielen rahmenlosen Motive stellen die Wandlogik jedoch in erheblichem

65 Jones 2019, 131f. beschreibt dies als einen Mehrwert des dritten Stils, der seine vermeintliche geringe materielle Wertigkeit kompensiere.

66 Gérard Genette führte für die Narratologie den Megriff der Metalepse ein (Genette 2018, 13f.): „[...] je crois raisonnable de réserver désormais le terme de métalepse à une manipulation - auf moins figurale, mais parfois fictionelle [...] - de cette relation causale particulière qui unit [...] l'auteur à son œuvre, ou plus largement le producteur d'une représentation à cette représentation elle-même“. Übertragen auf Bilder manifestieren sich Metalepsen in BildBrüchen; s. dazu Lorenz 2007; Wyler 2018. 
Maße in Frage. Vor den Sockeln können gewissermaßen ,aus dem Boden' Pflanzen sprießen. In der ,geschlossenen“ Mittelzone können z. B. Landschaftsvignetten die indefiniten Paneele als Bildgrund in Anspruch nehmen (Abb. 331), auf den Seitenpaneelen sind es häufig geflügelt-schwebende Figuren (Abb. 332), die die Statik und Solidität der Wand in Frage stellen. Die Wand kann sich aber wie im Tablinum der Casa di Marcus Lucretius Fronto auch unvermittelt, regelrecht, ornamenthaft ${ }^{*}$ öffnen (Abb. 292). Eine nunmehr immer häufiger gesuchte Ambiguität ergibt sich jedoch aus der entgegengesetzten ,Bewegung': dem Bezug des Bildes auf den Realraum. Die Protagonisten der Mythenbilder blicken oftmals aus dem Bild heraus, verwickeln den Bildbetrachter in Blickbeziehungen. Insbesondere bei den nun immer beliebteren Gartendarstellungen lassen sich konkrete Korrespondenzen zwischen real gebauter Architektur und realem Garten und gemalten Elementen ausmachen (Abb. 347). Gerade die mosaizierten Garten-Nymphäen (Abb. 407) sind durch die Integration von Naturmaterialien wie Muscheln und ihren blauen Grund schon in sich ambiguisiert und treten zu multimedialen Bild-Ensembles in Beziehung.

In all diesen Phänomenen kommt einerseits die Thematisierung des Realraums, andererseits aber auch des Bildraums und mit ihm der Bildlichkeit zum Tragen. Mit dem steigenden Interesse am Bild geht folglich ein innerbildlicher Diskurs zum ,Status' der Bildlichkeit einher.

\section{Decor-Ensembles}

Decor-Elemente stehen bereits innerhalb eines Raumes nicht für sich, sondern treten in komplexe Beziehungen zueinander. Darüber hinaus wurde Decor aber auch dazu eingesetzt, über den Einzelraum hinausgreifende Zusammenhänge herzustellen. Solche Korrespondenzen sind insbesondere für gleichzeitig wahrnehmbare Raum-Ensembles angestrebt worden - insbesondere für das Atrium und die ganz darauf geöffneten Räume. Die verschließbaren Räume wurden meist keiner Vereinheitlichung unterzogen, und doch lassen sich auch hier Pendant-Bildungen greifen. Entsprechende Strategien der raumübergreifenden ,Vernetzung lassen sich in allen Stilphasen nachweisen.

Im ersten Stil zeigte sich am Westatrium der Casa del Fauno ebenso wie am Atrium der Casa di Sallustio, dass Atrium, Alae und Tablinum als Ensemble begriffen wurden. Der Wandstuck war einem vergleichbaren Aufbau verpflichtet, setzte aber Alae und Tablina gleichzeitig durch Variationen vom Atriumsbereich ab. Insbesondere die Alae sind jedoch als spiegelbildliche Pendants begriffen worden. In der Casa del Fauno orchestrieren auch die Pavimente eine solche Raumordnung: Die Alae sind mit ihrem polychromen Lithostroton und mittigem Emblema aufeinander bezogen und darin zugleich vom unfigürlichen Atriumsraum abgesetzt.

In der Casa del Fauno sind auch die beiden das Tablinum flankierenden Triclinia als Pendants entworfen, die durch ähnliche, aber zugleich deutlich variierte Ausstattungsformen aufeinander bezogen sind. In manchen Häusern wurden auf diese Weise auch ausgewählte Cubicula zueinander in Beziehung gesetzt. So sind in der Casa della nave Europa (I 15,3; Plan 10) die beiden den Eingang rahmenden Cubicula (4) und (6) in gewisser Weise als Pendants angelegt worden. In beiden Cubicula ist die Orthostatenzone durch zwei Reihen isodom versetzter, breit gelagerter Tafeln ersetzt, in beiden Cubicula wird eine auffällige, plastische Gestaltung für die Oberzone gewählt, die den Blick in die Höhe lenkt. In Cubiculum (4) folgt auf das Epistyl eine hohe ionische Scheinkolonnade (Abb. 102), in Cubiculum (6) schließt die Oberzone mit einem auffälligen plastischen Rosettenfries ab (Abb. 114).

Sowohl in offenen Bereichen wie auch bei den Raum-Ensembles beziehen sich Korrespondenzen jedoch auf ästhetisch-formale Aspekte. Ein übergreifendes inhaltliches ,Programm‘ ergibt sich daraus nicht, auch wenn es dem Betrachter freilich offensteht, die unterschiedlichen figürlichen Elemente, wie sie etwa die Casa del Fauno besitzt, in einen assoziativen Zusammenhang zu bringen. Gerade die zahlreichen dionysischen und exotischen Elemente bieten sich für eine solche verdichtend-vergleichende Betrachtung an. 
Der zweite Stil mit seinen deutlich differenzierten Gestaltungsoptionen hält an der Schaffung von Raum-Ensembles fest. An den Atrien kommt dies darin zum Ausdruck, dass mit den geschlossenen Atriumsrückwänden üblicherweise auch in den auf das Atrium geöffneten Alae und Tablina ein geschlossener Wandaufbau einhergeht. Wie im Fall von Ala (7) der Casa del Labirinto können diese durch einen etwas aufwendigeren Decor mit vor die Wand gesetzten Säulen herausgehoben sein. Wenn der Ausstattungsprunk am Atrium gesteigert wird, so schließt dies die angrenzenden Räume mit ein. An den Rückwänden des tetrastylen Atriums (2) der Domus VI 17 [Ins. Occ.],41 (Abb. 225) sind gemalte Säulen auf ein hohes, verkröpftes Podium gestellt. Die Alae - als Pendants gestaltet - zeigen zwar eine geschlossene Rückwand, auf die Orthostaten-Tafeln und das Gesims folgt jedoch ein rotgrundiger Fries mit pickenden Vögeln (Abb. 225), während Tablinum (6) mit einer Megalographie ausgestattet ist. Decor erzeugt folglich visuelle Pendants und setzt Gestaltungsformen gezielt ein, um innerhalb einer Raumgruppe eine Hierarchisierung einzuführen.

Auch im zweiten Stil kann sich die Bildung von Pendants auf einzelne, auch in der Architektur als Pendants begreifbare Cubicula beziehen. So werden in der Casa di Cerere (I 9,13; Abb. 233) die beiden Cubicula (c) und (h) zu Seiten der Fauces durch das Aufgreifen einzelner Decor-Elemente aufeinander bezogen. In beiden Räumen wird ein polychrom gefasstes Opus africanum imitiert - in Cubiculum (c) allerdings in der Mittelzone des Alkovens (Abb. 196), in Cubiculum (h) in der Oberzone. Variiert werden auch die Pilasterspiegel - in Cubiculum (c) mit Gorgonen, in Cubiculum (h) mit Schildkröten. Die Ausstattung spielt folglich gezielt mit Angleichung und Variation. In der Casa di Ma. Castricius (VII 16 [Ins. Occ.],17) lässt sich ein solches Spiel für die Pavimente der nebeneinander liegenden Cubicula (23) und (24) greifen. Beide besitzen ein Mosaikpaviment aus Quadraten - in Raum (23) sind es schwarze Linien auf weißem Grund (Abb. 240), in Raum (24) weiße Linien auf schwarzem Grund (Abb. 241). Nur in Raum (23) ist in das Zentrum des Mosaiks ein Emblema mit tragischer Maske eingesetzt.

Besondere Relevanz erlangt die Pendant-Bildung durch Decor jedoch in Bezug auf die nunmehr immer beliebteren Raumgruppen. An der Raumgruppe des korinthischen Oecus der Casa del Labirinto lassen sich Pendant-Bildungen weniger gut greifen, da der Decor hier auf die Schaffung unterschiedlicher Atmosphären zielt. Andere Raumgruppen der Zeit setzen indes auf einen zentralen Hauptraum, der durch als Pendants konzipierte Räume gerahmt wird. In der Casa delle nozze d'argento (V 2,i; Plan 15) gilt dies für die Raumgruppe von Cubiculum (x), Festraum (y) und Cubiculum (z) auf der Südseite des Peristyls. Die Cubicula besitzen einen vergleichbaren, gelängten Zuschnitt, der die Aufstellung der Kline auf der dem Eingang gegenüberliegenden Schmalseite vorsieht. Die Pavimente verstärken die schon strukturell gegebene Raum-Analogie (Abb. 254). In beiden Räumen markiert ein Mosaikornament die Schwelle - in Cubiculum (z) ist es floral, in Cubiculum (x) geometrisch. Den Vorraum füllt jeweils ein bichromer Mosaikteppich, und auch dieser wird variiert. In Cubiculum (z) handelt es sich um ein Rautenmuster, in Cubiculum (x) um ein besonders unruhiges Muster, das sich aus schwarzen und weißen Dreiecken zusammensetzt. Das Schwellmosaik zum Alkoven rekurriert auf die Eingangsschwelle, sodass es in Cubiculum (z) floral, in Cubiculum (x) geometrisch ausfällt. Auch die Wandmalerei gliedert beide Räume in Vorraum und Alkoven, und auch hier ergibt sich ein Spiel mit Ähnlichkeiten und Unterschieden.

Im dritten Stil werden diese Strategien der Sequenzbildung noch systematischer als bis dahin umgesetzt. Durch die ,modischen' Schwarz-Weiß-Mosaiken können ganze Raumsequenzen schon am Boden als zusammenhängend charakterisiert werden. An der Casa di Marcus Lucretius Fronto hat sich zudem gezeigt, wie die Räume am Atrium gerade auch durch Kontraste aufeinander bezogen werden. So folgen auf das monochrom weiße Cubiculum (c) der schwarze Atriumsraum und das ausgesprochen bunte Tablinum (h). Das gerade nicht durch eine Blickbeziehung auf das Tablinum bezogene Cubiculum ( $\mathrm{g}$ ) erhält einen dem ,Schauraum 'vergleichbaren Wandaufbau. In der Villa von Boscotrecase ist das Farbmuster der Cubicula (15) und (16) invertiert und dadurch aufeinander bezogen (Abb. 371-372).

Am Beispiel der Casa di Giasone hat sich jedoch gezeigt, dass solche Korrespondenzen im dritten Stil über formale Parallelen und Unterschiede hinausreichen können. Die Raumgruppe am 
Peristyl wird auch durch die inhaltlichen Akzentsetzungen inszeniert, die die Mittelbilder vornehmen. Während das zentrale Triclinium (f) ein besonders repräsentatives, sakral aufgeladenes Setting entwirft, werden in den seitlich flankierenden Cubicula Liebesthemen gezeigt. Im südlichen Cubiculum (e) sind es Frauen, die sich in einer dramatischen Entscheidungssituation befinden, im nördlichen Cubiculum (g) Männer, die um eine Frau werben. Mit dem ,bilderreichen' dritten Stil können sich Korrespondenzen folglich auch auf die semantische Dimension der Räume ausdehnen.

\section{Alt versus Neu}

Von diesen Beobachtungen ausgehend stellt sich die Frage, inwieweit auch der Umgang mit ,alten` und ,neuen' Decor-Formen einer solchen Vorstellung von Kohärenz entspricht. Dass man in augusteischer Zeit durchaus in der Lage war, ,alte ' Decor-Formen des ersten und zweiten Stils von ,neuen“ Wandmalereien zu unterscheiden, bezeugt uns hinlänglich Vitruv ${ }^{67}$. Das Interesse an ,alten ' Ausstattungsformen kommt in besonders großen ,Stadtpalästen“ wie der Casa del Fauno und der Casa del Labirinto zum Ausdruck, in denen stilistisch homogene Wirkungsensembles bewahrt und wenn nötig durch restaurative Eingriffe aktiv gestaltet wurden. Alte Ausstattungsformen mögen als Verweis auf die lange Tradition der Familie oder als Ausweis eines altertümlichen Geschmacks wahrgenommen worden sein, die simplicitas der Wände mag einen adäquaten Rahmen für spezifische Handlungen abgegeben haben ${ }^{68}$. Gerade der erste Stil ist auch nach dem Aufkommen ,modernerer Ausstattungsformen als besonders passend für die Gestaltung von Atrien und Peristylen geschätzt worden, da er ein allansichtiges ,Bild“ einer Wand entwarf. Im Folgenden soll das Augenmerk jedoch auf einem anderen Aspekt liegen - wie nämlich Alt und Neu in pompejanischen Häusern zusammenspielten. Wolfgang Ehrhardt hat dieser Frage eine ausführliche Studie gewidmet ${ }^{69}$. Mit Blick auf die hier besprochenen Häuser soll jedoch ein spezifischer Aspekt - die Gestaltung zusammenhängender Raum-Ensembles - noch einmal unterstrichen werden.

So war man im Westatrium der Casa del Fauno ebenso wie im Ostatrium und im Peristyl der Casa del Labirinto darum bemüht, die Höfe als Ganzes in ihrem altertümlichen Erscheinungsbild im ersten Stil zu erhalten - die auf die Höfe geöffneten Räume eingeschlossen. Dies gilt nicht nur für die Wandgestaltung, sondern auch für die Pavimente. Dieses Streben nach Einheitlichkeit kommt in der Casa del Labirinto nicht zuletzt dadurch zum Ausdruck, dass man im Westatrium mit den neuen Möglichkeiten des zweiten Stils einen dem ,alten' Ostatrium vergleichbaren Raumeindruck erzeugte. Auch in der Casa di Giasone und der Casa di Marcus Lucretius Fronto bilden die Atriumsbereiche jeweils kohärente Ensembles - in diesen Fällen aus der Zeit des dritten Stils. In gleichzeitig wahrnehmbaren Raumbereichen wurde offenbar darauf geachtet hat, dass alte und neue Ausstattungsformen nicht abrupt aufeinandertrafen. Allerdings konnten innerhalb einer solch ,kohärenten` Ausstattung gezielt ,moderne‘ Akzente gesetzt werden. In der Casa di Sallustio (VI 2,4) behielten die Wände und Böden des Atriumbereichs ihr ,traditionelles‘ Erscheinungsbild im ersten Stil bei, im Zentrum des Atriums wurde jedoch in augusteischer Zeit ein BrunnenEnsemble mit Brunnenfigur ,nachgerüstet‘.

Dieses Streben nach Homogenität ${ }^{70}$ gilt nur bedingt für verschließbare Räume. An Atrien man denke noch einmal an das Ostatrium der Casa del Labirinto - konnten verschließbare Cubicula

67 Vitr. 7,5.

68 Laidlaw 1985, 45; Dickmann 1999, 252f.; Tybout 2001, 52; Oriolo - Zanier 2011, 494; McAlpine 2015; Wallace-Hadrill 1994, 25f. schließt aus dem Umstand, dass der Stil häufig in Fauces und auch am Atrium erhalten wurde, auf dessen ,öffentlichen' Charakter, eine Orientierung auf bestimmte Betrachterhaltungen ist ebenso denkbar; zur Diskussion auch Ehrhardt 2012, $11 \mathrm{f}$.

69 Ehrhardt 2012; sein Fokus liegt allerdings ausschließlich auf der Wandmalerei, andere Ausstattungselemente hat er nicht im Blick.

70 Bereits Laidlaw 1985, 45; Ehrhardt 2012, $77 \mathrm{f}$. 
Ausstattungen aus unterschiedlichen Stilphasen aufweisen. Für die Innenausstattung vermag Ehrhardts Detailstudie darzustellen, dass ,Stimmigkeit‘ wiederum ein wichtiges Decor-Prinzip darstell$\mathrm{te}^{71}$.

Das Streben nach Einheitlichkeit dürfte nach den Erdbebenzerstörungen 62 n.Chr. dafür verantwortlich gewesen sein, dass man nunmehr ganze Häuser neu ausmalte - man denke etwa an die Casa dei Vettii (VI 15,1) ${ }^{72}$. Wo dies nicht möglich war, sind nun aber bisweilen größere Inkongruenzen zu verzeichnen ${ }^{73}$. Bisweilen mag dies den Zwängen der Situation geschuldet gewesen sein, bisweilen aber auch einen neuen, stärker eklektischen Geschmack bedient haben, wie sich nicht zuletzt an den additiv komponierten Wandbildern der Zeit und den heterogenen SkulpturenEnsembles zeigt.

\section{Grand und Humble - die soziale Dimension von Decor}

Für die Frage nach der sozialen Dimension von Decor konnte eingangs Stil als visueller Ausdruck sozialer Zugehörigkeit ausgeschlossen werden ${ }^{74}$. Wallace-Hadrill kommt das große Verdienst zu, Decor-Qualität als strukturierende Größe im Haus begriffen zu haben. Verschiedene Qualitätsstufen würden eingesetzt, um Räume für ein bestimmtes Publikum, adäquat‘ auszustatten. Decor besäße somit eine unmittelbar soziale Aussagekraft. Intuitiv ist dies naheliegend: Für wirtschaftlichpragmatisch genutzte Hausbereiche, die vornehmlich von Sklaven genutzt wurden, ist eine deutlich einfachere Ausstattung zu erwarten (wenn auch vielfach nicht erhalten), denn für die Aufenthaltsräume.

Die vorausgegangenen Überlegungen sind einen Schritt zurückgetreten, um zunächst die Frage unterschiedlicher Decor-Qualitäten zu diskutieren. Als Anzeiger von Decor-Qualität erwiesen sich für die Wandmalerei die visuelle Differenziertheit (im ersten Stil etwa die Kleinteiligkeit des Wandaufbaus, im dritten Stil die Zahl der in ein Wandsystem integrierten Einzelformen) und die ikonographische Dichte (im ersten Stil etwa das Auftreten von Bildelementen überhaupt, im dritten Stil u.a. die Wahl von Mythenbildern), zu berücksichtigen wären zudem die Kosten für die verwendeten Farben $^{75}$. Am Boden kommen Materialqualitäten und technischer Aufwand hinzu. Im Medium der Skulptur geht es neben der Qualität der Ausarbeitung und der Komplexität und Innovation des Sujets auch um die Quantität. Allerdings entziehen sich decorative Einzelformen häufig einer linearen sozialen Hierarchisierung. Opera sectilia können schwerlich gegen Emblemata vermiculata ausgespielt werden, im dritten Stil ist der Wert eines Raumes mit Gartendarstellungen nicht mit einem Raum mit Mythenbildern verrechenbar. Eine räumliche ,Hierarchie‘ ergibt sich folglich nicht aus der visuellen Einzelform (etwa dem Vorhandensein eines Mythenbildes), sondern aus der Kumulation von, wertigen' Ausstattungsformen.

Tatsächlich weisen die architektonisch herausgehobenen, exzeptionellen Räume eines Hauses wie die Alexander-Exedra der Casa del Fauno, der korinthische Oecus der Casa del Labirinto oder das Tablinum der Casa di Marcus Lucretius Fronto eine Vielzahl an figürlichen Elementen auf, die sich als Anknüpfungspunkte für verschiedenste Diskurse anbieten. Aussagedichte wird zu einem zentralen Kriterium für Raumluxus, auch wenn dieser durch unterschiedliche Medien erzeugt wird und sich auf verschiedenste Inhalte beziehen konnte. Während die ,Bilder der Alexander-Exedra in fremde ,Welten' entführen (in fremde Zeiten und an fremde Orte), rekurrieren sie in der Casa del Labirinto auf Architekturen und (Bild-)Objekte, wie sie zumindest potentiell in einem reich aus-

71 Ehrhardt 2012, 73.

72 Ehrhardt 2012, 73f.

73 Demnächst ausführlich Christian Beck zur Insula IX, 5.

74 s.u. S. 39f.

75 Eine Rekonstruktion des Materialwerts wurde häufig auf der Basis von literarischen Quellen (bes. Plin. nat. 35) versucht, s. Ling 1991, 207; auch Wallace-Hadrill 1994, 150 diskutiert diesen Aspekt. 
gestatteten Haus denkbar sind. Im Tablinum der Casa di Marcus Lucretius Fronto visualisieren sie die für einen Otium-Kontext zentralen Diskurse: die Welt des Bacchus und der Venus. So unterschiedlich die visuellen Strategien und die thematischen Schwerpunktsetzungen ausfallen: Die zentralen Aufenthaltsräume zeichnen sich durch ein hohes Maß an ästhetischen und inhaltlichen Stimuli aus. In einfachen Wirtschaftsbereichen sind diese indes auf ein Minimum reduziert.

Während sich mit den Prunkräumen und ,Serviceräumen' die beiden Extreme auf der Ausstattungsskala ganz im Sinne von Wallace-Hadrill als ,Grand' und ,Humble‘ beschreiben lassen, gilt dies für das Gros der häuslichen Räume nicht. Ein wesentlicher Grund dafür liegt darin, dass die Funktion von Räumen und damit auch ihre soziale Aneignung ausgesprochen flexibel sind. Es ist damit nur folgerichtig, dass Ausstattungselemente keine lineare Raumhierarchie anzeigen. Vielmehr werden Decor-Formen in Abhängigkeit von Raumproportionen und damit zugleich auch in Abhängigkeit von potentiellen Betrachterhaltungen (mobil/statisch) gewählt. Der ,Wert ${ }^{\star}$ von Decor liegt somit insbesondere in seiner Passung für ein Ambiente.

Dies bedeutet, dass in allen Stilphasen Hofbereiche einen Decor erhalten, der das räumliche Setting strukturiert und schnell zu überblicken ist, während man für Aufenthaltsräume eine intensivere Wahrnehmung voraussetzt. Die Hofgestaltung - man denke an das in Schwarz gehaltene Atrium der Casa di Marcus Lucretius Fronto - erweist sich darin nicht als ,einfach' gegenüber den Aufenthaltsräumen, vielmehr liegt ihre Qualität in der Passung selbst ${ }^{76}$.

Im Vergleich der Aufenthaltsräume untereinander hat sich für die Casa del Labirinto und die Domus VI 17 [Ins. Occ.],41 darüber hinausgehend gezeigt, dass decorative Einzelformen auf ihre Wirkung im Gesamtzusammenhang, d.h. auf ihr Zusammenspiel mit Architektur und anderen Decor-Formen hin kalkuliert wurden. Im zweiten Stil hat dies etwa für gelängte Triclinia bedeutet, dass man auf komplexe Architekturprospekte zugunsten einer geschlossenen Wand verzichtet hat, im dritten Stil führte dies zu der Zurücknahme von Paviment-Decor zugunsten eines reichen Wandschmucks. Da uns die Raumdecken meist nicht erhalten sind, fehlt ein wichtiger Parameter bei der Einschätzung von Raumwirkungen. In allen Stilphasen zielen Decor-Formen darauf, Aufenthaltsräume mit einer der Architektur und damit auch potenziellen Nutzungsszenarien angemessenen Atmosphäre zu versehen.

\section{Historische Kontextualisierung}

Für den Wandel von Decor(-Prinzipien) in italischen Häusern sind in der Forschung zuvorderst ökonomische und politische Gründe geltend gemacht worden. Beide gängigen Deutungsmodelle werden im Folgenden diskutiert, es wird sich jedoch zeigen, dass sie den komplexen Phänomenen letztlich nicht gerecht werden. An ihre Stelle tritt am Ende des Kapitels der Vorschlag, die sich ändernden Ästhetiken und Semantiken - und mit ihnen den Wandel der Wohnatmosphären zuvorderst selbst als Movens zu begreifen. Diese Änderungen haben ihren Ort freilich in spezifischen ökonomischen, politischen, auch militärischen Konstellationen - sind auf diese aber nicht reduzierbar.

\section{Ökonomische und soziale Signifikanz}

In der Zeit zwischen dem 2.Jh.v.Chr. und dem 1.Jh.n.Chr. lassen sich die verschiedenen Veränderungen als ein wachsendes Interesse an häuslicher Ausstattung und mehr noch: als ein immer

76 Tybout 1993, 40 etwa hatte für den zweiten Stil angenommen, die öffentlichen Bereiche - bei ihm Atrium und Peristyl - seien einfach und konventionell ausgestattet, während die besonders aufwendigen Decor-Formen im privatintimen Kontext (in Triclinia und Cubicula) anzutreffen seien; ähnlich Dickmann 1999, 248f.; dies stellt jedoch die Passung von Decor für den Kontext nicht als eigene Decor-Qualität in Rechnung. 
stärkeres Interesse an Bildphänomenen beschreiben. Historisch gesehen fällt diese Bildbegeisterung in eine Zeit, die sich durch einen zunehmenden Luxus im Privatraum auszeichnet ${ }^{77}$. WallaceHadrill spricht von einer „consumer revolution“, die - von lateinischen Autoren heftig kritisiert zu immer neuen Formen sozialer Distinktion geführt habe ${ }^{78}$. Im Fokus der damaligen Kritik war insbesondere die Verwendung immer luxuriöserer Materialien wie Gold und Marmor, aber auch der Flächenbedarf der immer größeren ,Stadtpaläste‘. Es sind vor allem die Objekte und Räume, die mit der sozialen Praxis des Conviviums in Verbindung standen, auf die sich das neue Luxusgebaren richtete $^{79}$. Von Bildern ist nicht explizit die Rede, es stellt sich jedoch die Frage, ob sie als Teilphänomen der zunehmenden luxuria aufzufassen sind. Tatsächlich kann der Decor von Objekten und Architektur als eine Form der ,ästhetischen Arbeit“ betrachtet werden. Decor und insbesondere figürliche Darstellungen erhöhen den ästhetischen Wert von Objekten und Räumen. Es liegt daher zunächst nahe, ,Bilder selbst als Ausdruck von luxuria aufzufassen. Die zuvor skizzierte Decor- und Bildgeschichte gibt jedoch zu einer differenzierteren Betrachtung Anlass.

Im ausgehenden 2. und beginnenden 1.Jh.v.Chr. stellen ,Bilder' in verschiedener Hinsicht ein Randphänomen dar. Sie besetzen liminale Zonen, bleiben aber insgesamt eine Seltenheit. Eine erste ,Verdichtung، der Bilderfahrung ist in den Opera vermiculata zu greifen, die in aufwendigen Materialien realisiert sind und eine besondere Techne erfordern. Material und Technik, dann aber auch die visuelle Raffinesse und Eleganz der Darstellungen, machen diese Bilder zu Luxusobjekten. Noch in augusteischer Zeit werden Bilder in immer neuen Luxusgattungen realisiert - man denke an die Silberbecher von Boscoreale. Indem Bilder nun aber auch in preiswerteren Gattungen verfügbar werden, fungieren sie nicht mehr per se als Luxusanzeiger.

Tatsächlich hat die Forschung den augusteischen ,Bilderboom‘ zum Anlass für eine soziale Deutung des Bildphänomens genommen. Die Vervielfältigung von Bildern sei im Auftreten neuer sozialer Gruppen - den Freigelassenen - begründet. Die Kunst spiegele folglich den Geschmack einer neuen Mittelschicht ${ }^{80}$. Tatsächlich werden dabei jedoch Ursache und Wirkung verkehrt.

Schon im ersten und zweiten Stil waren Bilder Gegenstand der ,preiswerten` Wandmalerei, sie bleiben aber auf ausgesprochen wenige und zudem herausgehobene häusliche Kontexte beschränkt. Hat man die figürlichen Grabmalereien dieser frühen Zeit mit im Blick, so erweist sich der Verzicht bzw. die ,Marginalisierung‘ von Bildern im Haus als eine bewusste, ästhetische Entscheidung. Eine rein ökonomische Perspektive auf dieses Phänomen verbietet sich. In der Zeit des zweiten Stils und dann vor allem auch in augusteischer Zeit blieb es die Elite, die den Bilderboom befeuerte und immer wieder neue, kostspielige Medien dafür suchte. So stellten marmorne und bronzene Bildobjekte zunächst noch ein Distinktivum dar, das sich nur einzelne Hausbesitzer leisteten, ähnliches gilt für bebildertes silbernes Prunkgeschirr. Wenn Bilder nun in breiten Schichten und in großer Zahl rezipiert wurden, so spiegelt dies zuvorderst einen Geschmackswandel einen Wandel allerdings, an dem alle sozialen Schichten partizipierten. Gerade das breite gesellschaftliche Interesse an Bildern dürfte mit dafür verantwortlich gewesen sein, dass Bilder auch in finanziell erschwinglichen Medien wie der Wandmalerei, auf Öllampen und Keramik, hergestellt

77 Die Quellen sind in der Forschung bereits gesichtet und ausführlich diskutiert worden, weshalb hier der Verweis auf einen Einzelfall genügen kann. Deutlich wird dies an der Person des Gaius Octavius, der um 100 v. Chr. ein prunkvolles Haus, eine praeclara domus (Cic. off. 1,139), errichten ließ, das die Menge so sehr beeindruckte, dass sie ihn nach dem Besuch seines Hauses zum Konsul machte. Wenig später schon genügte das Haus nicht mehr den Ansprüchen der Zeit, Aemilius Scaurus ließ es abreißen und durch einen neuen Prunkbau ersetzen (Cic. off. 1,138; Plin. nat. 36,5).

78 Wallace-Hadrill 2010, 315-355. Bereits die lateinischen Autoren diskutieren kritisch, wann dieser Wandel historisch anzusetzen ist, s. Wallace-Hadrill 2010, 315-346; Lippolis 2017, 334-337.

79 Stein-Hölkeskamp 2005.

80 Leach 1982, 164: ,[...] the Augustan pinacotheca bears, I believe, the mark of middle-class imitation of the creations of wealth and power.“ S. 166: „With its format so easily adaptable to large or small spaces, the style was one that cut across the boundaries of prosperity, and many a modest house, not to mention commercial establishment, has its picture gallery rooms.“ Meyer 2012. 
wurden $^{81}$. Mit der Verfügbarkeit preiswerterer Bildmedien wurde die Lust am Bild zu einem Phänomen, das alle sozialen Gruppen der römischen Gesellschaft und alle Kontexte sozialer Interaktion umfasste.

\section{Politische Signifikanz}

Der ins Auge gefasste Untersuchungszeitraum des späten 2. und beginnenden 1.Jhs.v.Chr. ist in Italien in politischer Hinsicht eine bewegte Zeit. Vor diesem Hintergrund wurde in der Forschung vielfach der Versuch unternommen, einzelne Decor-Phänomene, insbesondere die vier pompejanischen Stile, als Ausdruck eines zeittypischen, durch politische Ereignisse motivierten Geschmacks zu beschreiben.

So manifestiert sich etwa für Rolf Tybout im zweiten Stil eine ,Realitätsflucht ${ }^{\star 82}$. Der ,Rückzug ins Private' würde in eine Zeit politischer Unsicherheit fallen. Für Klaus Fittschen stellen die prunkvollen Wände ein Surrogat dar, das den schwindenden Einfluss des Einzelnen kompensie$\mathrm{re}^{83}$. Ganz im Gegensatz dazu nimmt Andreas Alföldi für den zweiten Stil an, er würde für die erfolgreichen römischen Generäle auch im Privatraum eine anspruchsvolle Umgebung schaffen ${ }^{84}$. Etwas vorsichtiger formuliert John Clarke, der zweite Stil mit seinem Hang zu königlichen Assoziationen „fit the mood of the Late Republic“855. Einen anderen Ansatz wählt Andreas Grüner, der ästhetische Eigengesetzlichkeiten voraussetzt und Phänomene von Wandmalerei und Literatur parallelisiert. Der zweite Stil sei durch Raffinesse und eine neue Individualität geprägt, wie sie auch für die zeitgleiche Lyrik geltend gemacht werden könnten ${ }^{86}$.

Besonders intensiv wurde in der Forschung die politische Dimension des dritten Stils diskutiert, den man mit einer neuen augusteischen ,Ideologie‘ in Verbindung gebracht hat. In ihm komme eine neue klassizistische Auffassung zum Ausdruck, die mit den neuen augusteischen Werten der Würde (dignitas) und Einfachheit (simplicitas) einhergehe ${ }^{87}$ und die sich insbesondere die Senatoren zu Eigen gemacht hätten ${ }^{88}$. Im Gegensatz dazu hat man den dritten Stil auch als eine

81 Romizzi 2006, 24; Bragantini 2017, 283; kritisch zur Keramik Flecker - Haug 2017, 278; allgemein: Mayer 2012.

82 Tybout 1989, 371.

83 Fittschen 1976, 555.

84 Alföldi 1955, 35; Galinsky 1996, 179; Pappalardo 1990, 224.

85 Clarke 1991, 48.

86 Grüner 2004, 10-23; neue „Qualität“ des Hellenismus um 100 v.Chr. postuliert auf S. 34-37.

87 Zanker 1990, bes. 280: „Gemeinsam ist all diesen Versuchen [scil. frühen Beispielen des dritten Stils] die Abkehr von den unmittelbaren Vergegenwärtigungen von Aufwand und Luxus [...]. Daß aber diese Veränderungen etwa gleichzeitig mit den Bemühungen des Augustus um eine ,moralische Wende‘ beginnen, kann kein Zufall sein.“; vgl. Pappalardo 1990, 223; Clarke 1991, 49. 65; Platt 2009, 62f. will einen solchen Klassizismus insbesondere in den weißgrundigen Bildfeldern mit beruhigten Figurengruppen des beginnenden dritten Stils erkennen.

88 Torelli 1988, 39-43; darauf Bezug nehmend Pappalardo 1990, 224: „Es scheint, als habe der Zweite Stil noch das Lebensmodell der Ritter, Zöllner und Händler vor Augen, die sich durch die Eroberung des Orients bereichert hatten, während der Dritte Stil die Gesinnung der von Augustus zu Ehren gebrachten Senatorenklasse, der alten Aristokratie der patres, widerspiegelt. Diese hatte sich zwar den genau definierten ethischen Normen ihrer ordo und ihres status zu unterwerfen, konnte aber dennoch über Mittelsmänner und dank der sozialrechtlichen Einrichtungen des Patronats und der amicitia Geschäfte machen, ohne öffentlich in Erscheinung treten zu müssen (Torelli). “ S. 225: „Der Dritte Stil setzt Einfachheit an die Stelle der barocken Formen und der Szenarien des Reichtums, die den Zweiten Stil geprägt hatten, und bringt so die von Augustus auf politisch-ideologischer Ebene betriebene Verdrängung und Sublimation der luxuria in der Dekoration der Häuser zum Ausdruck. Die Senatorenaristokratie verpönte, wie man weiß, die luxuria und die Gewinnsucht der equites, publicani und mercatores. Sie zog es stattdessen vor, ihren status und ihre dignitas durch avaritia zu bekunden. Darüber hinaus darf nicht vergessen werden, daß sich die römische Gesellschaft aus scharf umrissenen sozialen Klassen zusammensetzte, den ordines, denen der Römer aufgrund seines Einkommens zugerechnet wurde. Jeder dieser Klassen entsprach ein genau definiertes, ethisches Modell, dessen Einhaltung von Zensoren kontrolliert wurde. Die patres lehnten deshalb die Kategorien „Geld“ und „Reichtum“ auch formal ab. In augusteischer Zeit wurden auch die Häuser als solche einfacher. Augustus selbst ging mit gutem Beispiel voran.“ 
,intime‘, private Form der Gestaltung aufgefasst und für diese Phase einen Rückzug ins Private postuliert ${ }^{89}$. Die Aristokratie sei im politischen Entscheidungsprozess unwichtig geworden und habe daher ihren Wirkungsrahmen ins Private verlegt ${ }^{90}$. Mit Blick auf die Villa von Boscotrecase, die sich im Besitz des Agrippa Postumus befunden haben könnte, wird aber auch die Idee formuliert, der Stil könnte am Kaiserhof entwickelt worden $\operatorname{sein}^{91}$. Das Kaiserhaus selbst habe die Maxime privater Zurückhaltung, die von der spätrepublikanischen Luxuskritik eindrücklich gefordert wurde, vorgelebt ${ }^{92}$. Im dritten Stil käme folglich der Kontrast zwischen aufwendigen öffentlichen Stiftungen der Elite und zurückgenommenen, privaten Ausstattungsformen zum Ausdruck $^{93}$. Mit der Verwendung fiktiver Bilder, die in Bezug auf surreale Architekturen präsentiert wurden, sei der Materialluxus sublimiert worden.

Die vorausgegangenen Überlegungen haben jedoch aufzeigen können, dass sich der dritte Stil durch eine Vielzahl neuartiger Bildformen, durch eine massive Komplexitätssteigerung der Wandmalerei, durch den Gebrauch dreidimensionaler Bildobjekte und schließlich durch eine extensive Steigerung von Luxusobjekten im Haus auszeichnet. All dies wird man nicht als Ausdruck von simplicitas werten können ${ }^{94}$. In der Steigerung der Architektur ins Phantastische, die sich mit der Darstellung von exotischen, monströsen und hybriden Körpern verbindet, lässt sich nicht nur die Repräsentation der augusteischen Aurea aetas, sondern auch ein subversives Potenzial erkennen, das dem augusteischen Klassizismus zuwiderläuft ${ }^{95}$. Eine politische Ausdeutung von Stilformen trifft somit auf gleich mehrere methodische Schwierigkeiten.

1) Eine politische Deutung setzt nicht nur eine trennscharfe Unterscheidung der vier Stile voraus, sondern macht auch eine exakte und damit historisierbare Datierung der ,ersten' Stilvertreter erforderlich. Für eine politisch-imperiale Aufladung des dritten Stils müsste vorausgesetzt werden, dass dieser in den Jahren nach 27 v.Chr. entstanden ist, als das politische System auf Augustus ausgerichtet wurde. Schon eine scharfe Trennung zwischen dem zweiten und dem dritten Stil ist jedoch schwierig.

2) Eine politische Deutung setzt weiterhin voraus, eine Zeit mit einem spezifischen und kohärenten Stilgeschmack zu verbinden und diesen politisch auszudeuten. Gerade für den dritten Stil konnte jüngst jedoch noch einmal betont werden, dass klassizistische und antiklassizistische Elemente bei der Erzeugung eines Decor-Raums, selbst eines einzelnen Wandbildes, zusammenwirken ${ }^{96}$. Simplifizierende Stilbeschreibungen verbieten sich daher ebenso wie eine platte Parallelisierung mit spezifischen politischen Deutungen. Umgekehrt kann die Bezeichnung einer stilistischen Qualität so allgemein ausfallen, dass sie für eine Charakterisierung einer zeitlichen Phase letztlich nicht taugt. Dies würde etwa auf die von Andreas Grüner vorgeschlagene Beschreibung des zweiten Stils als ,raffiniert' und einer Parallelisierung mit literarischen Formen der Zeit um 100 v.Chr. zutreffen. Auch der dritte Stil würde sich mit gutem Recht als ,raffiniert‘ beschreiben lassen. In ähnlicher Weise lässt sich das Kriterium der Wandöffnung

89 Grüner 2004, 165 argumentiert hier mit Cic. off. 2,2.; Sall. Catil. 4.

90 Wallace-Hadrill 1988, 72f.; 1994, 29; Grüner 2004, 137.

91 Zanker 1990, 281: "Dieser neue 'Stil' scheint mir nicht das Ergebnis eines schrittweisen Prozesses zu sein, wie es meistens dargestellt wird. Es muß ihm vielmehr ein bestimmtes Urbild, eine ,schlagende‘ künstlerische ,Erfindung“ zugrunde liegen [...].“; s. auch Zanker 1990, 282-284; Clarke 1991, 55.

92 So häufig in Bezug auf den Palatin postuliert, s. etwa Jones 2019, 94-101.

93 Jones 2019, 93.

94 Galinsky 1996, 186-189; mit Blick auf das Augustushaus, S. 189: „We are not dealing with a movement from lavishness to simplicity, but with a shift in decorative preferences.“

95 Platt 2009, 44.

96 Exemplarisch ausgeführt bei Platt 2009, bes. 58-63; resümierend S. 71: „This tension between the natural and the marvellous, the abundant and the restrained, the old and the new, explains divergent scholarly responses to Augustan painting, whereby it has been simultaneously criticized for its fanciful excess and praised for its classicizing elegance.“ 
problematisieren: Geöffnete Architekturprospekte treten gerade nicht nur im zweiten Stil auf, für den sie als Realitätsflucht gedeutet werden, sondern ebenso auch im vierten Stil ${ }^{97}$.

3) Politische Deutungen setzen darüber hinausgehend voraus, dass eine für den öffentlichen Raum entwickelte, politische Bildsprache im privaten Raum nicht nur übernommen, sondern auch politisch rezipiert worden wäre. Der dritte Stil ist aber wohl kaum als politisches Propagandainstrument geplant worden, um dann als solches flächendeckend im Privatraum rezipiert zu werden. Plausibler würde dieses Argument dann, wenn gezeigt werden könnte, dass Inhalte und Motive der augusteischen Staatskunst im privaten Kontext aufgegriffen würden. Entsprechende Versuche sind insbesondere in der Forschung der 80er und 90er Jahre unternommen ${ }^{98}$, jüngst jedoch einer eingehenden Kritik unterzogen worden. Exemplarisch sei auf die Debatte zu den Ägyptiaca verwiesen, die man traditionellerweise mit Actium verbunden hat. Zwar mögen entsprechende Motive im privaten Kontext durch die tagesaktuelle Politik an Beliebtheit gewonnen haben, verbreitet waren sie in Italien aber schon lange zuvor. Dies spricht für ganz andere, nicht-politische Interessen an diesem Thema ${ }^{99}$. Auch die mythologischen Paarbilder, die auf den Wänden beliebt werden, verzichten auf politische Anspielungen. Kommen etwa Mars und Venus zur Darstellung, so fehlen Verweise auf das iulisch-claudische Kaiserhaus gänzlich, vielmehr geht es um die Paarkonstellation.

4) Detailuntersuchungen zu einzelnen Decor-Formen - etwa zur Wandmalerei oder zu Pavimenten - konnten in jüngster Vergangenheit plausibel machen, dass sie lokalen bzw. regionalen Verwendungslogiken folgen. So lassen sich Unterschiede in den Wandsystemen bereits im Vergleich von Pompeji und Herculaneum greifen ${ }^{100}$. Diese regionale Spezifik von Decor macht es unplausibel, die Politik der Weltstadt Rom als übergreifendes Deutungsmodell für die Privathäuser der Städte Italiens zu begreifen.

5) Gegen einen Rückzug der Elite in das ,unpolitisch' Private spricht, dass man auch in privaten Kontexten in augusteischer Zeit auf Repräsentationsformeln zurückgriff, wie sie im öffentlichen Raum entwickelt worden sind.

Es zeigt sich somit, dass einzelne Aspekte, die politische Deutungen voraussetzen, einer Detailkritik zugeführt werden können. Vor allem aber sprechen zwei systematische Argumente gegen eine soziopolitische Vereinnahmung von Decor. Nimmt man eine Langzeitperspektive auf decorative Veränderungen ein, so wird deutlich, dass eine neue Lust am ,Bild“ schon zu Beginn des 1.Jhs.v.Chr. und damit lange vor Augustus greifbar ist. Eine nahsichtige Analyse vermag indes die große Vielfalt an visuellen Phänomenen in augusteischer Zeit offenzulegen. Nun kommen zahlreiche Neuerungen zusammen: das noch einmal sprunghaft gestiegene Interesse an Bildern, die Erfindung neuer decorativer Strategien (der ,dritte Stil'), das Auftreten neuer Medien und Inszenierungsformen, ein neues Repräsentationsbedürfnis, nicht zuletzt auch neue stilistische Präferenzen (Klassizismus). Zwar besitzen manche Bilder im Haus - insbesondere die seltenen Porträts der kaiserlichen Familie - das Potenzial, auf die öffentliche Politik Roms zu verweisen. Und freilich ist auch nicht ausgeschlossen, dass man beim Sujet von Mars und Venus an die Machthaber in Rom und ihre Genealogie denken konnte. Zwingend war dies jedoch nicht.

97 Schmaltz 1989, 219.

98 Exemplarisch: Zanker 1990.

99 Jüngst etwa Barrett 2019, 25. Allerdings ist das Ägypten-Thema schon als solches ambivalent besetzt, wie Galinsky 1996, 190 ausgeführt hat. Er verweist darauf, dass Augustus selbst für seine Hausausstattung auf Isis-Motive zurückgriff, obwohl er die Bedeutung des Isis-Kultus zu beschränken suchte. Augustus selbst habe folglich zwischen Ästhetik und Politik/Ideologie geschieden, was umso mehr für andere Privathäuser vorauszusetzen sei.

100 Zu bestimmten Werkstattvorlieben in Herculaneum, s. etwa Strocka 1987, 36; zu lokalen Varianzen der Estrichböden, s. Tang 2018, bes. 199-202. 


\section{Ästhetik, Atmosphäre, Lebensgefühl}

Ökonomische und politische Gründe sind als primäres Movens für die tiefgreifenden Veränderungen, welche die Wohnkultur erfasst haben, wenig plausibel. Der Wandel der Decor-Räume ließ sich in der vorausgehenden Untersuchung als ästhetisches, als semantisch-diskursives und damit auch als ein kulturell-mentales Phänomen beschreiben. Die ästhetischen Funktionen von Decor blieben zwischen dem 2.Jh.v.Chr. und dem 1.Jh.n.Chr. unverändert, wurden jedoch mit sich wandelnden Mitteln erreicht. Offenheit und Geschlossenheit, Symmetrie und Asymmetrie, Zentralität und Liminalität, ,Bild‘ und ,Ornament‘, Licht, Farbe und Material, wurden immer wieder neu zueinander in Beziehung gesetzt.

Dabei können Decor-Formen wie im ersten Stil auf eine ,Streuung، der Aufmerksamkeit zielen, die den Raum als Ganzes erlebbar macht - Bilder sind in diesem Konzept naturgemäß eher hinderlich. Aufmerksamkeit kann aber auch gezielt gesteuert werden, indem der Decor wie im zweiten Stil spezifische Perspektiven einnimmt und vorgibt. Mit Formen der Aufmerksamkeitslenkung und -streuung kann wie im dritten Stil zudem gezielt gespielt werden, indem klar strukturierte Pseudoarchitekturen zwar eine Orientierung im Raum schaffen und ein wertiges Raumerlebnis erzeugen, zugleich aber die Bildelemente intensive Aufmerksamkeit für sich beanspruchen.

Mit diesem ästhetischen Wandel ging ein stetig wachsendes Interesse an Bildphänomenen einher. Das Spiel mit verschiedenartigen Medien und Präsentationsformen darf per se als intellektuelle Leistung aufgefasst werden. Zugleich wird aber auch ein immer stärker wachsendes Interesse an Bildern als diskursiven Medien greifbar. Während die reduzierten Bilder des erstens Stils mit der Darstellung von dionysischen Trabanten, von Xenia, Fischen, gefährlichen und exotischen Tieren bis hin zu nilotischen Szenen in sehr allgemeiner Weise Luxus, Lebensgenuss und Exotik thematisieren, konkretisieren die Architekturprospekte des zweiten Stils mit ihrer prunkvollen gemalten Ausstattung die Vorstellung eines Luxusambiente. Mit den Mythenbildern des dritten Stils ist eine Bildsprache gefunden, um Körper- und Rollenbilder zur Diskussion zu stellen, vor allem aber auch, um Liebe und Erotik in das Haus einzuführen ${ }^{101}$.

Schließlich war die Bildervermehrung auf pragmatischer Ebene voraussetzungsreich. Erst die Erschließung der Marmorsteinbrüche in Luni ermöglichte es, den gestiegenen Bedarf nach Luxusmaterial zu befriedigen, das für eine umfängliche Skulpturenproduktion benötigt wurde ${ }^{102}$. Auf technisch-handwerklicher Ebene bedurfte es neuer Verfahren der Bildreproduktion - im Bereich der Wandmalerei ebenso wie im Bereich der Skulptur ${ }^{103}$. Viele der ,Innovationen ' hatten Vorläufer, auf die Augustus für seine ,öffentlichen' Bilder zurückgreifen konnte und ihnen dadurch im privaten Kontext zu großer Bedeutung verhalf.

Schon auf der pragmatischen Ebene der Decor-Produktion ergeben sich somit intensive Verflechtungen zwischen dem privaten und dem öffentlichen Raum. Ähnliches ließe sich für eine Vielzahl von Decor-Strategien aufzeigen, die im Haus und in der Öffentlichkeit gleichermaßen zum Tragen kommen ${ }^{104}$. Nicht weniger ist eine Durchdringung auf sozialer Ebene vorauszusetzen: Es sind dieselben Menschen, die im privaten Raum als Dominus und im öffentlichen Raum als Amtspersonen agieren. Und doch ist die Sphäre des Hauses nicht auf Kategorien des Öffentlichen reduzierbar. Im häuslichen Bereich kommen spezifische ästhetische, semantisch-diskursive und damit auch atmosphärische Bedürfnisse zum Tragen.

101 So allgemein Zanker 2015, 76, der dann aber auch im Haus politische Themen im Mythos gespiegelt sehen möchte.

102 Unter Caesar, dann von Augustus weitergeführt; vgl. Pensabene - Gasparini 2015, $97 \mathrm{f}$.

103 Signifikant ist in dieser Hinsicht der Fund von Gipsabgüssen der Tyrannentöter in Baiae, die auf entsprechende Reproduktionsmechanismen schließen lassen - vgl. von Hees-Landwehr 1982.

104 Dazu ist eine weitere Monographie geplant. 


\section{Ausblick: Leistungen der Bilder}

Die historische Fallstudie erlaubt einen Ausblick auf ein besonders bedeutsames Sonderphänomen von Decor: die Bilder. So stellt sich die grundsätzlichere Frage, warum Bilder gemacht werden (die Produktionsperspektive), wie sie wahrgenommen werden (die Rezeptionsperspektive) und welchen Eigenwert sie besitzen. Jede Zeit wird auf diese Grundfragen ihre eigenen Antworten finden. Die nachfolgenden Überlegungen nehmen ihren Ausgangspunkt noch einmal im hier betrachteten Untersuchungszeitraum.

Der Auftraggeber eines Bildes, in unserem Zusammenhang zumeist der Hausbesitzer, trifft eine Kaufentscheidung nach seinen Interessen. Er investiert einen bestimmten Geldbetrag und sieht einen bestimmten Nutzungs-/Präsentationskontext vor. Bilder und Bildobjekte sind daher immer auch Gegenstand von Konsumenten-Entscheidungen. Der Auftraggeber kann, muss aber nicht, Einfluss auf Form und Inhalt eines Bildes nehmen. Gerade in stark standardisierten Gattungen ist es wahrscheinlicher, dass er seine Auswahl in Bezug auf verfügbare Bildobjekte trifft. Insbesondere bei Ausstattungsformen, die wie Wandmalerei und Pavimente unmittelbar auf die Architektur bezogen waren und bei denen eine Anpassung an räumliche Gegebenheiten besonders geschätzt wurde, darf man eine aktive Rolle der Handwerker unterstellen. Für die Auswahl bestimmter Bilder darf man ästhetische Gründe (die ,Verschönerung، eines Ortes, sein ornamentum) und semantische Gründe (Kommunikation) geltend machen. Beide Motivationen sind mit spezifischeren Interessen verknüpft: soziale Ambitionen (soziale Repräsentation), die Demonstration von Bildung/Wissen, die Zurschaustellung kultureller Zugehörigkeit bzw. auch soziokultureller Abgrenzung, religiöse/ rituelle Bedürfnisse, die Kommunikation und Verhandlung sozialer Normen oder die Artikulation spezifischer Wünsche und Träume. Darin unterscheiden sich die Interessen, die Privatleute an ihre Bilder richten, erheblich vom öffentlichen Kontext. Kaum eine Rolle spielen in den Häusern nämlich politische Diskurse (diese sind auch beim Convivium verpönt), Werbebotschaften (die üblicherweise auf Verkaufsräume beschränkt bleiben) oder auch technisch-pragmatische Bilder wie die Kartierung von Besitztümern.

Die antiken Betrachter und ihre Rezeptionsformen lassen sich nur indirekt greifen. Der spezifische räumliche Kontext eines Bildes und seine Medialität geben jedoch einen Hinweis auf die beteiligten Akteursgruppen, ihre körperliche Beziehung zum Bild, die möglichen Handlungen und die unterschiedlichen Aufmerksamkeitsebenen. All diese Aspekte haben Einfluss auf die Relevanz, Bedeutung und Wirkung von Bildern. Die Wahrnehmung hängt von der Aufmerksamkeit und dem Interesse ab, die der Betrachter mitbringt. Wenn er gerade intensiv mit einer Handlung beschäftigt ist, wird er die Bilder nur flüchtig wahrnehmen. Seine konkrete Beschäftigung - etwa die Teilnahme an einem Gastmahl - wird sich auf die Wahrnehmung des Bildes auswirken, er nimmt die Umgebung und damit auch die Bilder in Bezug auf seine Handlung wahr. Die Präsentationsform von Bildern kann aber dazu beitragen, bestimmte Betrachterhaltungen zu befördern. Wenn etwa die Mosaikemblemata des ersten und zweiten Stils den Conviviums-Teilnehmern auf dem Kopf und in Schrägsicht präsentiert werden, wird sich eine eher beiläufige Wahrnehmung einstellen, während die Mittelbilder des dritten Stils den Lagernden regelrecht entgegentreten. Auch die Komplexität dieser Bilder und Bild-Ensembles bietet sich für eine intensive Auseinandersetzung beim Gelage an. Durch die kontextuelle Einbettung entstehen jeweils spezifische Erwartungen und Zuschreibungen an Bilder. Eine besonders hohe Aufmerksamkeit dürfte Bildern zuteil worden sein, die in rituelle Handlungen eingebettet waren. In den Häusern der späten Republik und frühen Kaiserzeit bleiben solche Bilder - Darstellungen des Larenkults wie auch magisch-apotropäische Bilder zunächst noch selten. Dennoch darf man für solche rituell gebrauchten ,Kultbilder annehmen, dass die Akteure ihnen ein eigenes Handlungspotenzial (agency) zuschrieben. Die Wirkung der Bilder ist folglich maßgeblich von Bildformen, Inszenierungskontexten und Wahrnehmungsformen abhängig. 
Bilder lassen sich allerdings nicht auf die von ihren Auftraggebern intendierte Bedeutung und die Zuschreibungen der Betrachter reduzieren. Trotz aller postmodernen Dekonstruktionen sind Bilder widerständig gegen willkürliche Rezeptionen. Sie besitzen einen Eigenwert, der sich aus ihrer spezifischen Ästhetik und ihrem Inhalt (Semantik) ergibt. Bilder ,passieren' im Moment ihrer Wahrnehmung und tragen aktiv zu diesem Ereignis bei. Hier kommt die ,Macht' der Bilder ins Spiel. Sie erregen Aufmerksamkeit, organisieren das Sehen im Raum, geben Orientierung. Durch ihre Ikonographie können ,starke‘ Bilder bestimmte (auch unerwünschte) Diskurse und sogar Handlungen beeinflussen. Gerade wenn Bilder menschliche Körper darstellen, können sie die Befriedigung von körperlichen Wünschen (Essen, Sex) provozieren. Bilder können, müssen aber nicht, die Erwartungen der Betrachter erfüllen; sie können auch überraschen oder mit den Erwartungen des Betrachters spielen. In Bezug auf die ästhetische Dimension kann man an Trompe-l'œil-Effekte oder auch an Darstellungen des ,Hässlichen“ (z.B. Monster) denken. Sie können also überraschen, unterhalten, aber auch schockieren. Aufgrund ihres widerständigen Charakters haben Bilder ein subversives Potenzial. Sie können die soziale Ordnung bedrohen. Bilder besitzen einen Bildkörper, in den sich ihre Nutzungsgeschichte einschreibt: Bilder tragen Spuren ihrer eigenen Geschichte. Sie manifestieren und inkorporieren Erinnerung. 
